Revista Latinoamericana de la Papa 19 (2): 42-67

ISSN: 1853-4961

http://www.papaslatinas.org/revista.html

\title{
Comportamiento fisiológico de variedades de papa (Solanum tuberosum L.) bajo condiciones de sequia
}

\section{P. Mamani-Rojas ${ }^{1}$; J. François-Ledent ${ }^{2}$}

Recibido: 09/08/2015

Aceptado: $21 / 09 / 2015$

Disponible en línea: Diciembre 2015

\section{Resumen}

En las regiones montañosas andinas de Tiraque, Cochabamba, Bolivia y en dos años consecutivos se evaluaron seis variedades de papa contrastantes en su tolerancia a la sequía, en condiciones semi-controladas usando pequeños contenedores apropiados para la siembra y bajo una cubierta tipo tinglado que sirvió de resguardo de la lluvia. El objetivo fue identificar parámetros fisiológicos en la papa que sean sensibles a la sequia y que estén asociados con la productividad del cultivo. Se aplicaron tres regímenes de agua: $\mathrm{R} 0=$ riego a capacidad de campo (testigo), R1 = sequía al inicio de la tuberización (sequía temprana) y R2 = sequía a un mes del inicio de la tuberización (sequía tardía). Se ha observado que los parámetros fisiológicos Resistencia Difusiva Estomatal (RDE), Transpiración, Potencial Hídrico Foliar (PHF) y Contenido Relativo de Agua Foliar (CRAF), fueron muy variables entre las variedades estudiadas. La sequía aumentó la RDE y redujo el PHF, la Transpiración y el CRAF de todas las variedades. En condiciones de sequía existe una relación inversa entre RDE y Transpiración, RDE y PHF y una relación directa entre PHF y CRAF. De todas las variedades estudiadas, destaca Luk'y porque mantiene una baja transpiración aun en condiciones de RDEs bajas, presenta bajas tasas de transpiración y reduce en menor medida su CRAF. Este comportamiento expresa que su capacidad de regulación del agua es distinta al resto de las variedades. Los mecanismos fisiológicos mas asociados con el rendimiento del cultivo de papa son la RDE, la Transpiración y el PHF.

Palabras claves adicionales: Estrés hídrico, resistencia difusiva estomatal, transpiración, potencial hídrico foliar, contenido relativo de agua foliar.

\section{Physiological behavior of potato varieties (Solanum tuberosum L.) under drought conditions}

\section{Summary}

In the Andean highland regions of Tiraque, Cochabamba, Bolivia in two consecutive years, six varieties of potatoes contrasting in their tolerance to drought were evaluated in semicontrolled conditions by using small containers suitable for planting and under a shed cover that served as protector from the rain. The aim was to identify physiological parameters in potatoes that are sensitive to drought and are associated with crop productivity. Three water schemes were applied: R0 = irrigation at field capacity (witness), R1 = drought at the beginning of tuber (early drought) and $\mathrm{R} 2=$ a month drought tuber initiation (late drought). It has been observed that the physiological parameters Diffusive Stomatal Resistance (DSR), transpiration, Leaf Water Potential (LWP) and Leaf Relative Water Content (LRWC), were

\footnotetext{
Autor para correspondencia. Correo electrónico:p.mamani@proinpa.org

1 Investigador ecofisiólogo, suelos y producción agrícola de la Fundación PROINPA, Cochabamba, Bolivia.

Ex Profesor de la Université Catholique de Louvain la neuve, Bélgica
} 
highly variable among the varieties studied. Drough increased the DSR and reduced the DSR, transpiration and the LRWC of all varieties. In drought conditions, there is an inverse relationship between RDE and transpiration, DSR and LWP, and a direct relationship between LWP and LRWC. Of all the varieties studied, Luk'y stands out because it maintains a low transpiration and reduces its LRWC to a lesser extent. This behavoir expresses that its ability to regulate water is different from other varieties. The physiological mechanisms associated more with the potato crop yield are the DSR, transpiration and the LWP.

Additional Keywords: Water stress, stomatal diffusive resistance, transpiration, leaf water potential, leaf relative water content.

\section{Introducción}

Cuando una planta está sometida a condiciones diferentes a las condiciones óptimas para su vida, se dice que está sometida a estrés. Si bien las especies o variedades difieren en sus requerimientos óptimos, también difieren en su susceptibilidad a un determinado estrés (Hsiao, 1973; Levitt, 1980).

Los sistemas biológicos han adoptado el concepto físico de "tensión - deformación" (estrés - strain) para analizar los procesos que ocurren cuando una planta se encuentra sometida a una situación de estrés. El estrés biológico es cualquier factor ambiental capaz de producir una deformación potencialmente nociva para un organismo (Levitt, 1980). Según Gaspar et al. (2002), estrés es una condición fisiológica alterada, causada por factores que tienden a perturbar el equilibrio y strain es cualquier cambio físico y químico producido por dicho estrés.

Una planta responde de diferentes formas al estrés, lo que depende de la intensidad del mismo: 1) en condiciones de un estrés cuya intensidad es menor al "limite elástico" de la planta, ocurre una deformación la cual vuelve a su estado normal cuando termina el estrés (respuesta reversible), 2) en condiciones de un estrés cuya intensidad sobre pase el "limite elástico" de la planta, la deformación puede ser de dos tipos: a) una "deformación elástica" que cuando el estrés desaparece la planta recuperará su estado inicial (respuesta reversible) y b) una "deformación plástica" que cuando el estrés desaparece la planta no logra recuperar su estado inicial (respuesta irreversible) (Valladares, 2004). El límite elástico, es la tensión máxima que un material natural, artificial o biológico puede soportar sin sufrir deformaciones permanentes (Berrocal, 1998)

En la naturaleza las plantas están expuestas a muchas tensiones o estreses, como la sequía, la salinidad, las heladas, las inundaciones, el calor, el estrés oxidativo, la toxicidad de metales, etc (Jaleel et al., 2009). El conocimiento de los mecanismos de resistencia al estrés permite comprender los procesos evolutivos implicados en la adaptación de las plantas a un ambiente adverso y predecir hasta cierto punto la respuesta vegetal al incremento de esta adversidad asociada en muchos casos al cambio global (Valladares, 2004).

Los mecanismos fisiológicos, morfológicos y metabólicos que utilizan las plantas en respuesta a los estreses pueden agruparse en: mecanismos de tolerancia, mecanismos de resistencia y mecanismos de escape o evasión. Los mecanismos de tolerancia permiten a las plantas adaptarse y soportar el estrés debido a cambios de comportamiento temporal que le permiten compensar el déficit de humedad, ya sea por una menor pérdida de agua por los estomas o simplemente reduciendo al mínimo sus funciones. Los mecanismos de resistencia de la planta le permiten soportar el déficit de humedad debido a mecanismos controlados por genes involucrados directamente en el proceso de síntesis de proteínas y almidones o por 
genes acondicionadores que dan a la planta características especiales de resistencia al déficit hídrico. Los mecanismos de escape o evasión son aquellos que permiten eludir los efectos de la sequía debido a que las plantas completan su maduración antes de la llegada del estrés (precocidad) o promueven una mayor exploración de agua por las raíces (Boyer, 1996; Prasad, 1996).

La sequía es considerada el principal factor ambiental que limita el crecimiento y la productividad de los cultivos en todo el mundo, especialmente en las zonas semiáridas como el Mediterráneo (Chaves et al., 2003). Su incremento no solo es el resultado de una menor precipitación anual sino también de un patrón de distribución estacional diferente, con lluvias torrenciales e irregulares intercalado con periodos secos de escasa utilidad para el rendimiento del ecosistema (Rambal y Debussche, 1995; Reichstein et al., 2002). La tolerancia a este estrés es muy compleja, debido a la intrincada red de interacciones entre los factores de estrés y diversos fenómenos moleculares, bioquímicos y fisiológicos que afectan el crecimiento y desarrollo de la planta (Razmjoo et al., 2008).

Uno de los principales efectos de la sequía es en la fotosíntesis debido a que la primera respuesta de la planta es el cierre de sus estomas para evitar la pérdida de agua lo que también obstruye el ingreso de $\mathrm{CO}_{2}$ (Flexas y Medrano, 2002). La reducción en la asimilación de $\mathrm{CO}_{2}$ genera un desequilibrio entre la actividad fotoquímica y la electrónica del fotosistema II, requisito fundamental para la fotosíntesis (Souza et al., 2004). El efecto sobre la fotosíntesis y la transpiración depende de la rapidez, la gravedad y la duración de la sequía (Rouhi et al., 2007). También se reduce la fotosíntesis neta durante el estrés por sequía (Rouhi et al., 2007). El Fv/Fm de la clorofila fluorescente, la tasa de transpiración y la conductancia estomática disminuyen con el aumento de estrés por sequía (Miyashita et al., 2005).

No hay consenso sobre el sitio primario de la reducción en la fotosíntesis y tampoco hay consenso si fotorreacciones en las membranas tilacoides $\mathrm{o}$ reacciones bioquímicas del ciclo de Calvin son los más afectados. La mayoría de los experimentos no distinguen entre el estrés hídrico y el estrés por calor. Estos factores están correlacionados positivamente, pero es deseable medir sus efectos por separado (Galmés et al., 2011).

Por otra parte, las plantas para adaptarse a la sequía también utilizan mecanismos que reducen la deshidratación del tejido, ya sea manteniendo su potencial hídrico o tolerando bajos potenciales hídricos. Esto se logra minimizando la pérdida de agua por el cierre de los estomas, acumulando metabolitos osmóticamente activos, reteniendo agua por las proteínas o incrementando la resistencia del mesófilo al flujo del agua (Smirnoff, 1993; Jaleel et al., 2007). Como respuestas al estrés también se incrementa la biosíntesis del ácido abscísico (ABA) y las expresiones de transcripción y actividades de nuevas proteínas (Radin, 1981; Robertson et al., 1985).

En relación a la papa (Solanum tuberosum L.), la sub especie tuberosum es la más consumida en el mundo pero también es la más susceptibles al estrés por sequía (Weisz et al., 1994). Por otra parte la sub especie andigena que es cultivada en diferentes pisos altitudinales de Los Andes, desde Venezuela hasta el norte de Argentina (Huamán y Ross, 1985), está más adaptada a las condiciones climáticas adversas. El genoma tetraploide de ambas subespecies permite la generación híbrida (Kumar y Kang, 2006; Tai y Tarn, 1980); por lo tanto, la sub especie Andigena es un candidato ideal para el estudio de genes relacionados con la tolerancia a la sequía que en el futuro permita hacer introgresión en Tuberosum (Vásquez et al., 2008). 
Estudios del efecto de la sequía en la fisiología de diferentes variedades de papa muestran que tanto en condiciones de una sequía temprana como de una sequía tardía, existe interacción entre los factores variedad y sequía para los parámetros fisiológicos potencial hídrico foliar (PHF), conductancia estomatal y fotosíntesis (Deblonde et al., 2001). Martínez y Moreno (1992), en condiciones de riego normal no observaron diferencias varietales para la conductancia foliar, fotosíntesis, potencial de agua y en la acumulación de prolina. Por tanto arguyen que bajo estas condiciones estos parámetros no pueden ser usados para identificar variedades tolerantes a la sequía. En condiciones de estrés hídrico encontraron diferencias varietales en estas variables así como en la habilidad de recuperación y en el rendimiento.

El efecto del estrés hídrico sobre el rendimiento de papa depende de la respuesta global de procesos morfofisiológicos, tales como la fotosíntesis, la expansión de la superficie de la hoja, la senescencia foliar, la partición de asimilados, el inicio de la tuberización, entre otros (Galmés et al., 2011). Uno de los primeros efectos de la sequía en la papa es la reducción de su tasa de fotosíntesis debido al aumento de la resistencia estomática (Moorby et al., 1975). Los parámetros fisiológicos como la resistencia estomática y la tasa de fotosíntesis, podrían explicar las variaciones genotípicas en papa en condiciones de sequía si estuvieran relacionados con parámetros que definen el estado hídrico de la planta como el potencial hídrico de la hoja y el contenido relativo de agua de las hojas (Tourneux et al., 2003).

A pesar de la disminución de la conductancia de $\mathrm{CO}_{2}$ en la hoja a intensidades leves y moderadas de sequía, cuando no hay limitaciones bioquímicas para la fotosíntesis, se ha descrito ampliamente el aumento del uso eficiente del agua estimado a partir de la relación entre la tasa de asimilación neta (AN) de $\mathrm{CO}_{2}$ y la conductancia estomática (CE) (Medrano et al., 2009). El aumento de la relación AN/CE puede atribuirse a las diferencias en la disminuciones relativas de las dos resistencias principales como son el del estoma y del mesofilo de la hoja al $\mathrm{H} 2 \mathrm{O}$ y el CO2 (Soolanayakanahally et al., 2009; Duan et al., 2010). En este sentido, la exploración de la variabilidad en la respuesta fisiológica a la sequía en cultivares de papa adaptados localmente pueden proporcionar pistas esenciales para mejorar el rendimiento del cultivo (Tuberosa et al., 2007). Para Tourneux et al. (2003) los genotipos de papa sometidas a la sequía son diferentes en términos de su respuesta en rendimiento, morfología y fisiología.

El objetivo del presente estudio fue identificar parámetros fisiológicos en la papa que sean sensibles a la sequia y que estén asociados con la productividad del cultivo. Los parámetros fisiológicos identificados podrán ser usados como indicadores de material tolerante a la sequia y/o permitirán establecer una tipología de variedades tolerantes a la sequía en las condiciones de Bolivia. En un artículo anterior, Mamani y Ledent (2014) han publicado el comportamiento morfológico y agronómico del mismo material vegetal que se utilizó en el presente artículo.

\section{Materiales y métodos}

El estudio se realizó en dos campañas consecutivas en la provincia Tiraque de Cochabamba, Bolivia ubicada a 3540 msnm, 17.4 latitud sur, 65.7 longitud oeste y cuyas temperaturas mínima, máxima y media son de $2,20,11^{\circ} \mathrm{C}$ respectivamente y su precipitación anual de $530 \mathrm{~mm}$. El ensayo del primer año fue planeado para ganar experiencia en los tratamientos hídricos y en el comportamiento de las variedades. Esta experiencia permitió adecuar los tratamientos hídricos y elegir mejor las variedades para el ensayo del segundo año. 
En ambos ensayos, el ambiente en el que se realizó el estudio fue una cubierta grande con techo de plástico y paredes laterales descubiertas (tipo tinglado), que permitió un mejor control del agua de riego y no alteró mayormente las otras variables climáticas. Para la siembra se utilizó tierra del lugar la cual se dispuso en contenedores de madera de 0.4 x 0.7 x 0.9 $\mathrm{m}$ de alto, ancho y largo respectivamente. El número de plantas por contenedor fue de seis distribuidas a lo largo del contenedor en dos filas de a tres.

En ambos casos el diseño estadístico utilizado fue el de Bloques Completos al Azar con un arreglo factorial de 6 x 3 (6 variedades y 3 tratamientos hídricos), con cuatro repeticiones, totalizando 72 unidades experimentales (contenedores).

Las variedades utilizadas en el primer año fueron:

- Solanum berthaultii L. , especie silvestre, tardía y resistente a la sequía

- Jaspe, variedad híbrida, semi tardía y tolerante

- Waych'a, variedad andígena, semi tardía y susceptible

- Desirée, variedad tuberosum, precoz y susceptible

- Ch'aska, variedad andígena, tardía y tolerante

- Yungay, variedad híbrido, tardía y tolerante.

Por su comportamiento atípico en relación a las especies cultivadas y su baja productividad, para el segundo año de estudio se sustituyó la especie Solanum berthaultii L., por la especie Solanum jusepzukii, Buk., más conocida como Luk'y que es una variedad amarga que se caracteriza por ser tardía y resistente a la sequía. El resto de las variedades se mantuvo para su evaluación en el segundo año.

Los tratamientos hídricos fueron:
R0 = Riego normal a capacidad de campo (testigo)

R1 = Sequía al inicio de la tuberización de cada variedad (sequía temprana)

R2 = Sequía a un mes luego del inicio de la tuberización de cada variedad (sequía tardía)

Como es lógico entender, el inicio de la sequía R1 y R2 para una y otra variedad fue diferente porque el inicio de tuberización entre ellas fue diferente. En el caso de la especie $S$. berthaultii, que tuvo un inicio de tuberización muy tardía, se consideró un inicio de sequía para R1 y R2 similar al de Waych'a por ser la variedad más conocida. Se trató de mantener una duración de la sequía R1 similar para todas las variedades, es decir 35 días de suspensión completa del riego salvo un riego ligero a los 21dias para evitar la muerte de aquellas variedades más susceptibles. La duración de la sequía R2 no se pudo ajustar a una duración similar a la de R1 debido a que algunas variedades presentaban una mayor susceptibilidad a la sequía producto de su mayor estado de desarrollo. Este aspecto indujo a ajustar la duración de la sequía $\mathrm{R} 2$, en función del estado del follaje que presentaba cada variedad para lo cual se realizaba observaciones diarias de la sintomatología de la planta. El riego de recuperación en R2 se realizó antes que la planta ingrese en un estado de marchitez total (ver Tabla 1).

Debido a la gran variabilidad en el inicio de tuberización entre las variedades, en el segundo ensayo el inicio y duración de los tratamientos de sequía se ajustaron a uno solo (Tabla 1), vale decir al inicio de tuberización de la variedad Waych'a por ser la más conocida. La duración de R1 fue de 27 días menor a los 35 días del R1 del primer ensayo debido a que se buscó reducir el riesgo de muerte de las variedades más sensibles.

Los tratamientos de sequía del segundo ensayo fueron: 
$\mathrm{R} 0=$ Riego normal a capacidad de campo (testigo)
$\mathrm{R} 1$ = Sequía temprana (Suspensión del riego al inicio de la tuberización de la variedad testigo Waych'a)

$\mathrm{R} 2$ = Sequía tardía (Suspensión del riego a un mes luego del inicio de la tuberización de la variedad testigo Waych'a).

Tabla 1. Inicio y duración de los tratamientos de sequía en el primer y segundo ensayo.

\begin{tabular}{|l|cc|cc|}
\multicolumn{4}{|c}{ Paried. } & \multicolumn{3}{|c|}{ R1 } & \multicolumn{2}{c|}{ R2 } \\
& Inicio & Duración & Inicio & Duración \\
\hline S. berth. & 54 & 35 & 82 & 21 \\
Jaspe & 34 & 35 & 62 & 17 \\
Waych'a & 54 & 35 & 82 & 11 \\
Desirée & 25 & 35 & 53 & 19 \\
Ch'aska & 49 & 35 & 78 & 21 \\
Yungay & 43 & 35 & 71 & 21 \\
\hline
\end{tabular}

R1 = Sequía al inicio de la tuberización de cada variedad

R2 = Sequía a un mes del inicio de la tuberización de cada variedad El inicio corresponde a los días después de la siembra.

La duración esta expresado en días.

En ambos ensayos los riegos se aplicaron con una frecuencia de dos veces por semana, en volúmenes que variaron de acuerdo al contenido de humedad en el suelo, el cual fue evaluado en forma gravimétrica (Piñas, 2012). La siguiente relación permitió determinar los volúmenes de agua de riego: $\mathrm{V}=[$ ( $\mathrm{CC}$ Ha )/ 100 ] x Da x P x A

Donde:

- $\mathrm{CC}=$ capacidad de campo $=17 \%$

- $\mathrm{Ha}=$ humedad actual del suelo determinado gravimétricamente dos veces por semana

- $\mathrm{Da}=$ densidad aparente del suelo $=1300 \mathrm{Kg} / \mathrm{m}^{3}$

- $\mathrm{P}=$ profundidad del suelo $=$ de 0.2 a $0.4 \mathrm{~m}$ (según el crecimiento de la raíz).

- $\mathrm{A}=$ área a regar en las cajas $=0.7 \mathrm{~m} \times 0.9 \mathrm{~m}=$ $0.63 \mathrm{~m}^{2}$.

Las evaluaciones fisiológicas de ambos ensayos se realizaron durante los períodos de sequía de los tratamientos. En el primer ensayo se evaluó el Potencial Hídrico Foliar (PHF), la Resistencia Difusiva Estomatal (RDE) y la Transpiración. En el segundo ensayo se evaluó el Contenido Relativo de Agua Foliar (CRAF), la RDE, la Transpiración y el PHF.

Para determinar el PHF se utilizo una Camara de Presión (PMS Instrument Co., Corvallis, Oregon, USA) proceso descrito por Scholander et al. (1965), y para

\begin{tabular}{|l|cc|cc|}
\hline \multicolumn{1}{|c|}{ Varied. } & \multicolumn{3}{|c|}{ R1 } & \multicolumn{2}{c|}{ R2 } \\
& Inicio & Duración & Inicio & Duración \\
\hline Luk'y & 55 & 27 & 82 & 15 \\
Jaspe & 55 & 27 & 82 & 15 \\
Waych'a & 55 & 27 & 82 & 15 \\
Desirée & 55 & 27 & 82 & 15 \\
Ch'aska & 55 & 27 & 82 & 15 \\
Yungay & 55 & 27 & 82 & 15 \\
\hline \multicolumn{4}{r}{ R1 = Sequía temprana } \\
R2 $=$ Sequía tardía
\end{tabular}

determinar la RDE y la Transpiración se utilizo un Porómetro modelo LICORN 1500. El PHF se evaluó en forma semanal a horas 6:30 y a horas 14:00, en dos plantas laterales de cada unidad experimental y en una hoja completamente expandida del tercio superior de cada planta. Las evaluaciones con el porómetro para medir la RDE y la Transpiración se realizo en forma semanal y en dos horas del día (8:00 y 14:00). Se eligió las dos plantas centrales de cada unidad experimental y una hoja completamente expandida del tercio superior de cada planta.

El CRAF se evaluó a horas 6:30 para lo cual se midió previamente el Peso Fresco de las hojas (PF), las cuales luego se introdujeron en agua por 24 horas para determinar su Peso de Saturación (Psat.) y finalmente se introdujeron en un horno a $72{ }^{\circ} \mathrm{C}$ por 48 horas para determinar su Peso Seco (PS). Se utilizó la siguiente relación: $\mathrm{CRAF}=(\mathrm{PF}-\mathrm{PS}) /($ Psat $-\mathrm{PS}) . \mathrm{El}$ rendimiento en ambos ensayos se evaluó en las seis plantas de cada unidad experimental. Fuera del análisis independiente de cada variable fisiológica, también se procedió al análisis de regresión entre ellas y su correlación con el rendimiento. 


\section{Resultados y discusión}

\section{A. Resistencia difusiva estomatal (RDE)}

Las Figuras 1 y 2 presentan la variación en el tiempo de la RDE de seis variedades de papa en condiciones de riego normal R0 (plantas control) medidos en dos horas (8:00 y 14:00), de dos ensayos consecutivos respectivamente $(\mathrm{p}<0.05)$. Se observa que la RDE de todas las plantas fue más estable el segundo año (por debajo de $2 \mathrm{~s} / \mathrm{cm}$ ) respecto del primer año que sobre pasó este nivel ( $\mathrm{p}$ < 0.05). También se observa que la RDE fue muy diferente entre variedades, siendo el primer año la más baja la de $S$. berthaultii (menor a 1 $\mathrm{s} / \mathrm{cm}$ ) y la más alta la de Ch'aska (mayor a $5 \mathrm{~s} / \mathrm{cm}$ a los $82 \mathrm{dds}$ ) y el segundo año la más baja de Jaspe (menor a $1 \mathrm{~s} / \mathrm{cm}$ ) y la más alta de Luk'y (mayor a $2 \mathrm{~s} / \mathrm{cm}$ a los 91 dds), ( p < 0.05). Tourneux et al. (2003) en condiciones similares también encontraron RDEs altas para Luk'y por encima de otras variedades. También se observa que algunas variedades como Jaspe, Waych'a, Ch'aska y Yungay (Luk'y en el segundo ensayo) tienen una RDE mayor a horas 8:00 que a horas 14:00, lo que demuestra que en condiciones de buena humedad en el suelo estas variedades no limitan el flujo interno del agua cuando la demanda evapotariva es alta. $S$. berthaultii parece escapar a esta aseveración. En general, se conoce que la RDE es afectada por las condiciones climáticas, como la irradiación (Dwelle et al., 1983), temperatura (Ku et al., 1977) y la humedad del aire (Hall et al., 1999).

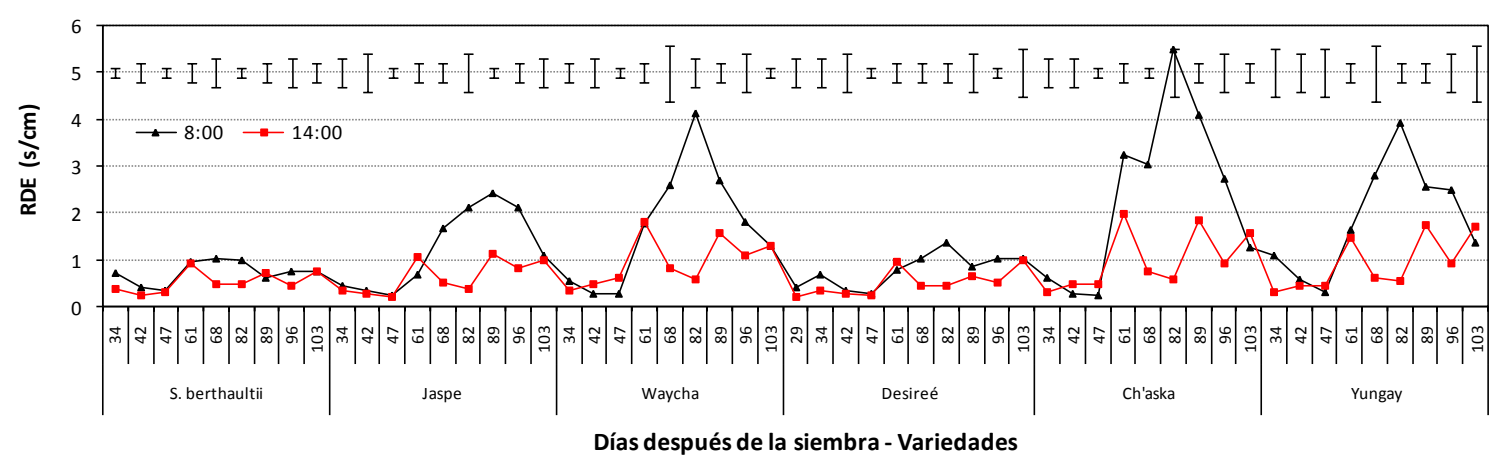

Figura 1. Variación de la Resistencia Difusiva Estomatal (RDE) de seis variedades de papa, en dos horarios de evaluación y bajo condiciones de riego normal (R0). Resultados del primer ensayo. Las barras en la parte superior denotan la Diferencia Mínima Significativa (DMS) para cada momento de evaluación $(\mathrm{p}<0.05)$.

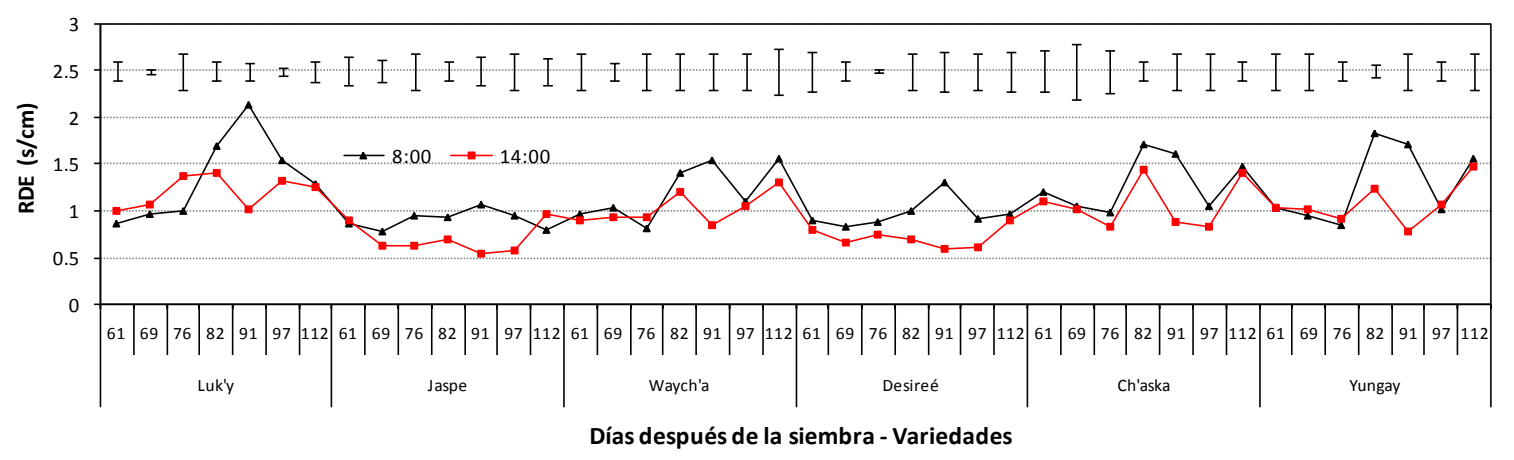

Figura 2. Variación de la Resistencia Difusiva Estomatal (RDE) de seis variedades de papa, en dos horarios de evaluación y bajo condiciones de riego normal (R0). Resultados del segundo ensayo. Las barras en la parte superior denotan la Diferencia Mínima Significativa (DMS) para cada momento de evaluación $(\mathrm{p}<0.05)$. 


\section{ARTÍCULO DE INVESTIGACIÓN}

Revista Latinoamericana de la Papa 19 (2): 42-67 http://www.papaslatinas.org/revista.html

Las Figuras 3 y 4 presentan la variación en el tiempo de la RDE de seis variedades de papa en condiciones de sequía $(\mathrm{R} 1=$ sequía temprana y $\mathrm{R} 2$ = sequia tardía) medidos en dos horas (8:00 y 14:00), de dos ensayos consecutivos respectivamente $(\mathrm{p}<0.05)$. Todas las variedades incrementaron su RDE por efecto de la sequía, unas más que otras ( $\mathrm{p}<0.05)$. En el primer ensayo (Figura 3) se observa que en ambos horarios (8:00 y 14:00) Waych'a, Ch'aska, Yungay y Jaspe incrementan su RDE en mayor proporción respecto de las plantas control (R0), especialmente por efecto de la sequía tardía (R2). Por otra parte, $S$. berthaulti y Desireé presentaron las menores diferencias con respecto a sus controles $(p<0.05)$. En el segundo ensayo (Figura 4) la tendencia es similar pero se incluye a Luk'y como una variedad con baja RDE en condiciones de sequía. Contrariamente, en condiciones de sequía, Tourneux et al. (2003) encontraron que la variedad Luk'y presentó mayor RDE que otros genotipos. También encontraron RDEs mayores en la tarde que en la mañana, especialmente al final del período de sequía e indican que esto demuestra la capacidad de las plantas para limitar las pérdidas de agua por evaporación cuando la demanda está en su máximo. La recuperación de la RDE en las plantas con sequia fue muy rápida para todos los genotipos estudiados. Al día siguiente del riego de recuperación no se observó ninguna diferencia significativa entre el control (R0) y los tratamientos de sequía R1 y R2.

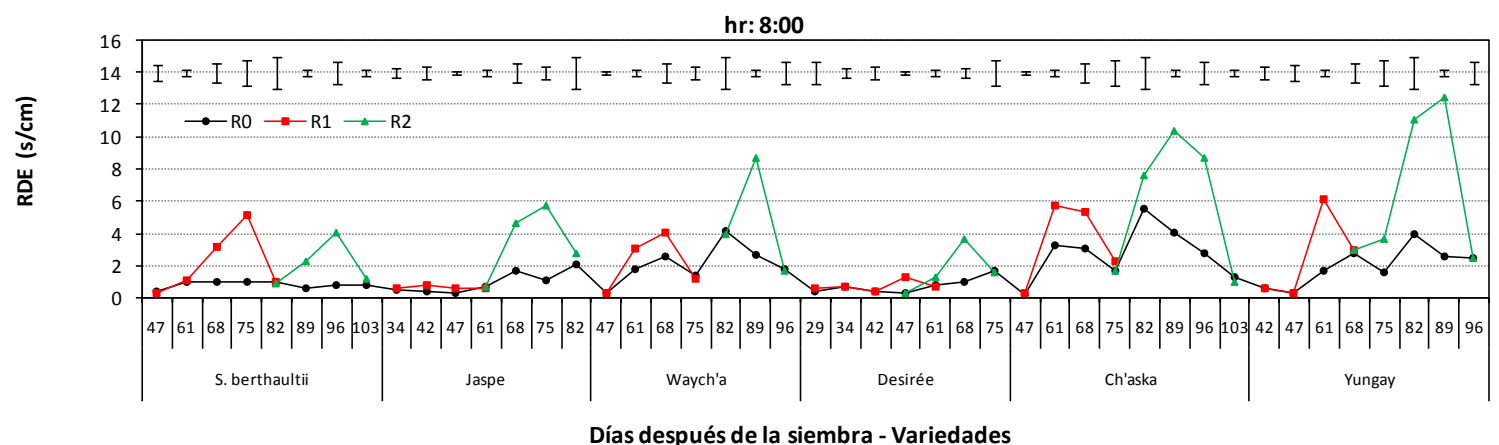

Días después de la siembra - Variedades

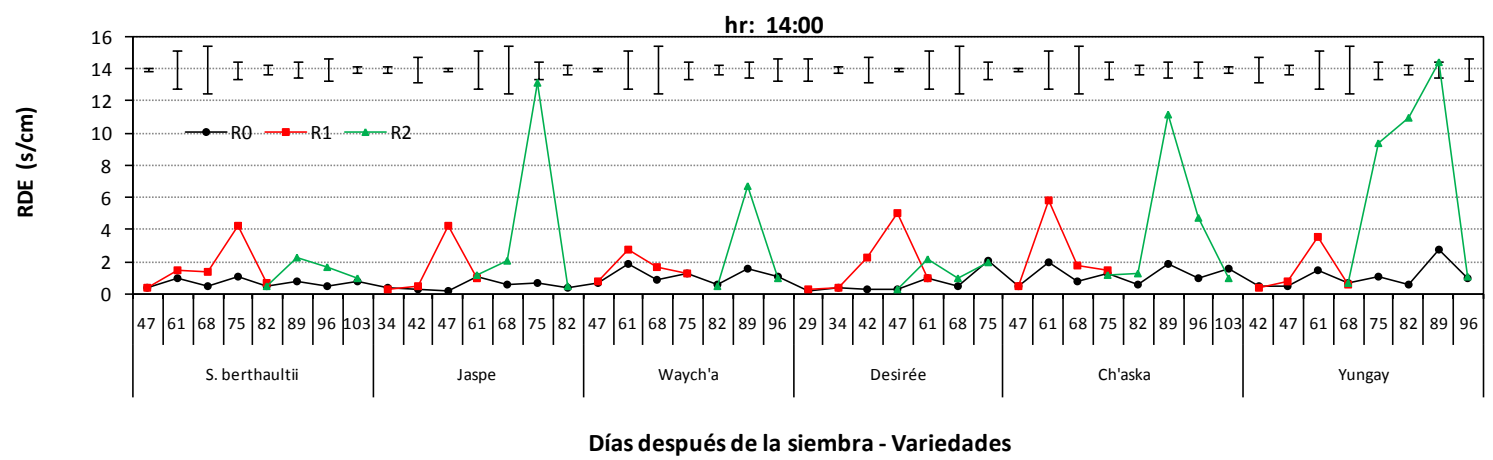

Figura 3. Variación de la Resistencia Difusiva Estomatal (RDE) por efecto de la sequía en seis variedades de papa y en dos horarios de evaluación. Resultados del primer ensayo, donde: R0 = Riego normal; R1 = Sequía inicio tuberización y R2 = Sequía a un mes del inicio de la tuberización. Las barras en la parte superior denotan la Diferencia Mínima Significativa (DMS) para cada momento de evaluación $(\mathrm{p}<0.05)$. 

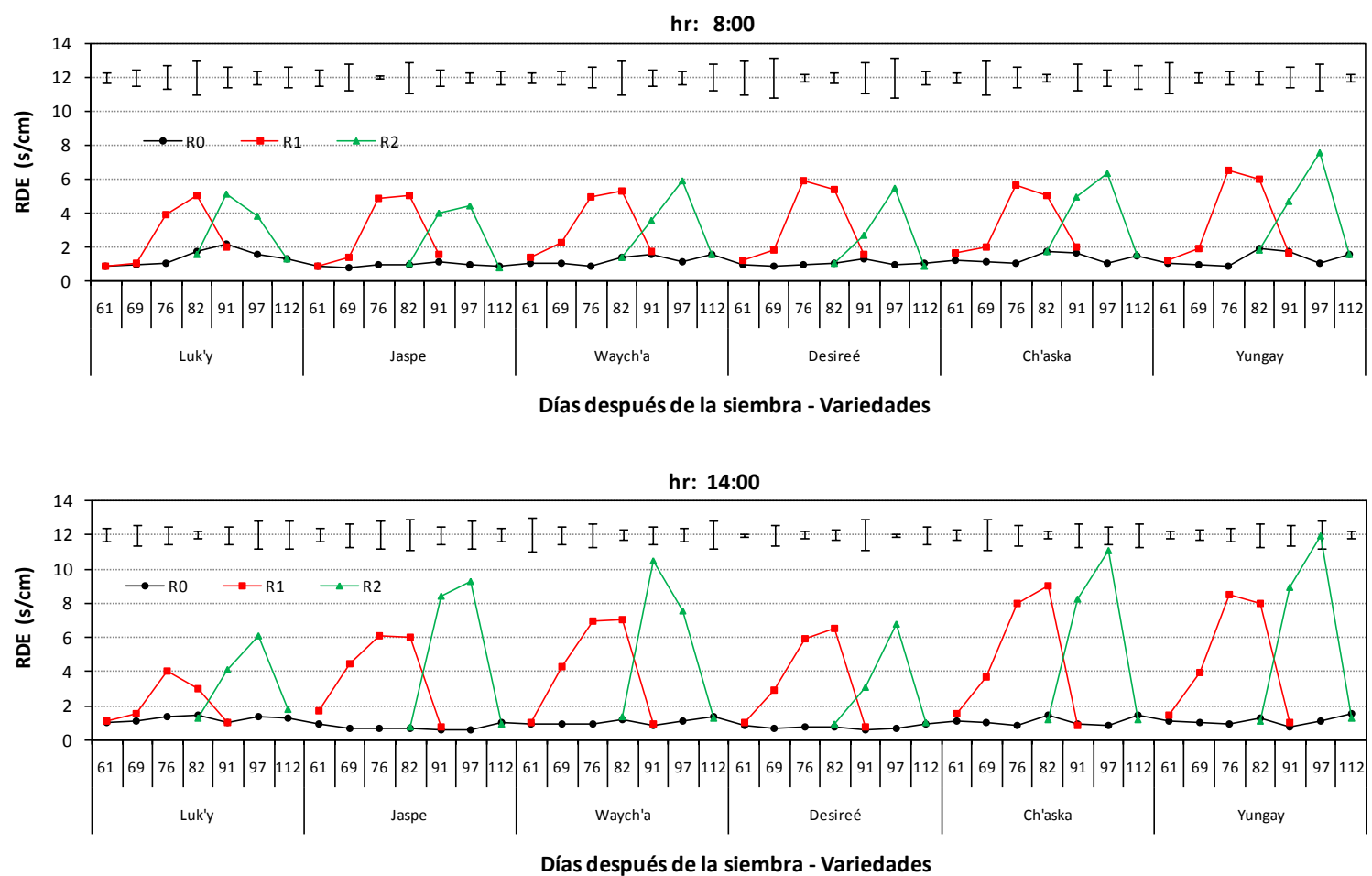

Figura 4. Variación de la Resistencia Difusiva Estomatal (RDE) por efecto de la sequía en seis variedades de papa y en dos horarios de evaluación. Resultados del segundo ensayo, donde: R0 = Riego normal; R1 = Sequía temprana y R2 = Sequía tardía. Las barras en la parte superior denotan la Diferencia Mínima Significativa (DMS) para cada momento de evaluación $(\mathrm{p}<0.05)$.

\section{B. Transpiración}

Las Figuras 5 y 6 presentan la variación en el tiempo de la Transpiración de seis variedades de papa en condiciones de riego normal R0 (plantas control) medidos en dos horas (8:00 y 14:00), de dos ensayos consecutivos respectivamente $(p<0.05)$. Se observa que los niveles de Transpiración variaron entre uno y otro año, siendo mayor en el primero $(p<0.05)$. En ambos ensayos $\mathrm{y}$ en condiciones de un riego normal (R0) se pudo determinar que la Transpiración es mayor a horas 14:00 que a horas 8:00 (p < 0.05). Esto está demostrando que en condiciones de buena humedad en el suelo, las plantas limitaron menos la salida de agua por transpiración cuando la demanda evaporativa es alta. Zyalalov (2004) señala que la principal fuerza motora que impulsa al agua en su viaje a la parte aérea es la transpiración lo que supone que las hojas presenten los potenciales hídricos más negativos.

También se observa diferencias marcadas en la transpiración según el genotipo. En el primer ensayo (Figura 5) S. berthaulti, Jaspe y Desireé mantienen los niveles más altos de transpiración $(\mathrm{p}<0.05)$. Por otra parte, Waych'a, Ch'aska y Yungay presentaron la más baja transpiración ( $\mathrm{p}$ $0.05)$.

En el segundo ensayo (Figura 6) la tendencia es similar pero Luk'y sobresale como la variedad con menor transpiración. Este comportamiento de Luk'y muestra que su capacidad de regulación del agua es diferente al resto, aún en condiciones de buena humedad en el suelo. 


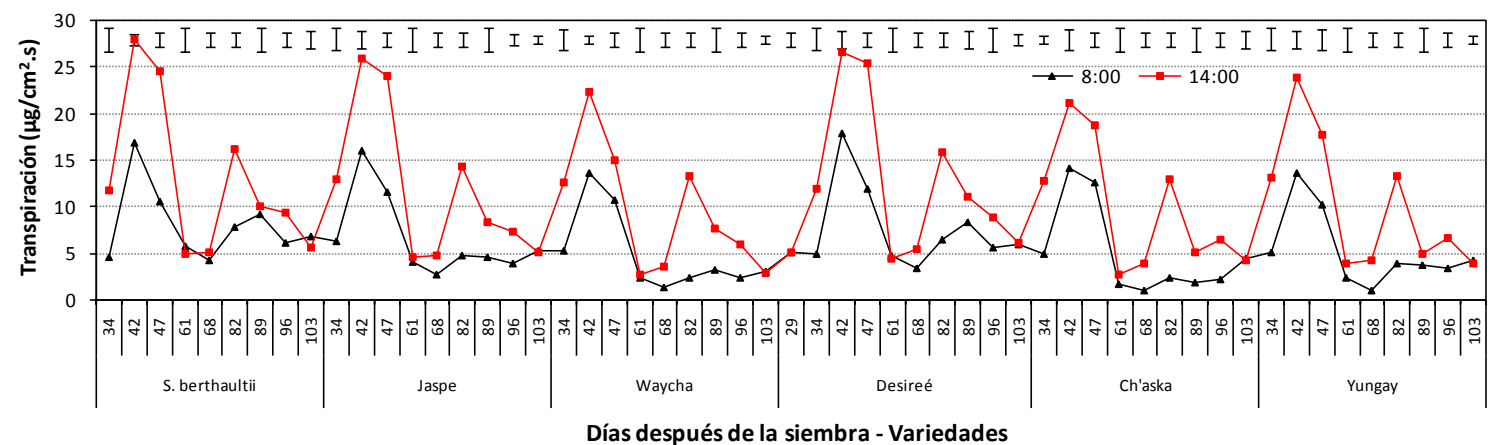

Figura 5. Variación de la Transpiración de seis variedades de papa, en dos horarios de evaluación y bajo condiciones de riego normal (R0). Resultados del primer ensayo. Las barras en la parte superior denotan la Diferencia Mínima Significativa (DMS) para cada momento de evaluación $(\mathrm{p}<0.05)$.

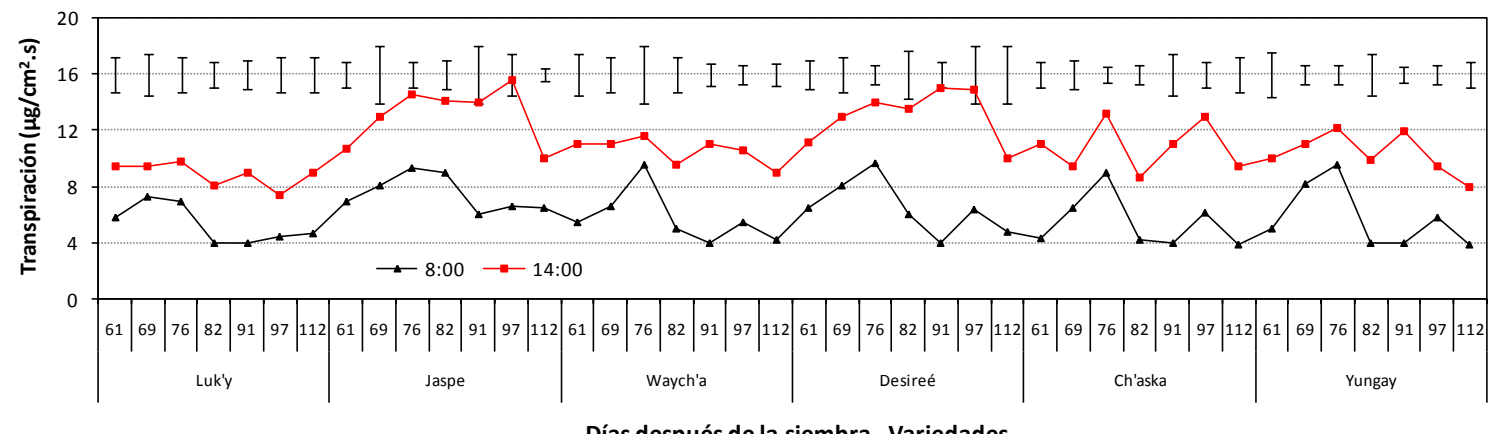

Figura 6. Variación de la Transpiración de seis variedades de papa, en dos horarios de evaluación y bajo condiciones de riego normal (R0). Resultados del segundo ensayo. Las barras en la parte superior denotan la Diferencia Mínima Significativa (DMS) para cada momento de evaluación $(\mathrm{p}<0.05)$.

Las Figuras 7 y 8 presentan la variación en el tiempo de la Tranpiración de seis variedades de papa en condiciones de sequía $(\mathrm{R} 1=$ sequía temprana y $\mathrm{R} 2=$ sequia tardía) medidos en dos horas $(8: 00$ y 14:00), de dos ensayos consecutivos respectivamente. Todas las variedades redujeron su Transpiración en condiciones de sequía $(\mathrm{p}<0.05)$. En ambos horarios (8:00 y 14:00) S. berthaulti, Jaspe y Desireé (primer ensayo) redujeron su Transpiración en mayor proporción respecto de las plantas control, especialmente por efecto de la sequía tardía (R2). Waych'a, Ch'aska y Yungay redujeron menos por efecto de ambas sequías (R1 y R2) ( $<$ 0.05). En el segundo ensayo la tendencia es similar incluyendo la de Luk'y. Según Taiz y Zeiger (2006) los estomas son los responsables de la mayor proporción de pérdida de agua en las plantas, cuya apertura y cierre en condiciones de sequía según Leung y Giraudat (1998), está regulado por el acido abscisico (ABA). Valladares (2004) por su parte señala que las plantas pueden amortiguar la sequía respondiendo de cuatro formas: i) variando la superficie foliar por donde la planta transpira y pierde agua, ii) regulando la apertura estomática, iii) modificando la conductividad hidráulica entre las distintas partes de la planta y iv) adaptando la raíz para mejorar la captación de agua. Las tres primeras están estrechamente relacionadas y el cuarto está relacionado con una sequía severa en condiciones de campo. 

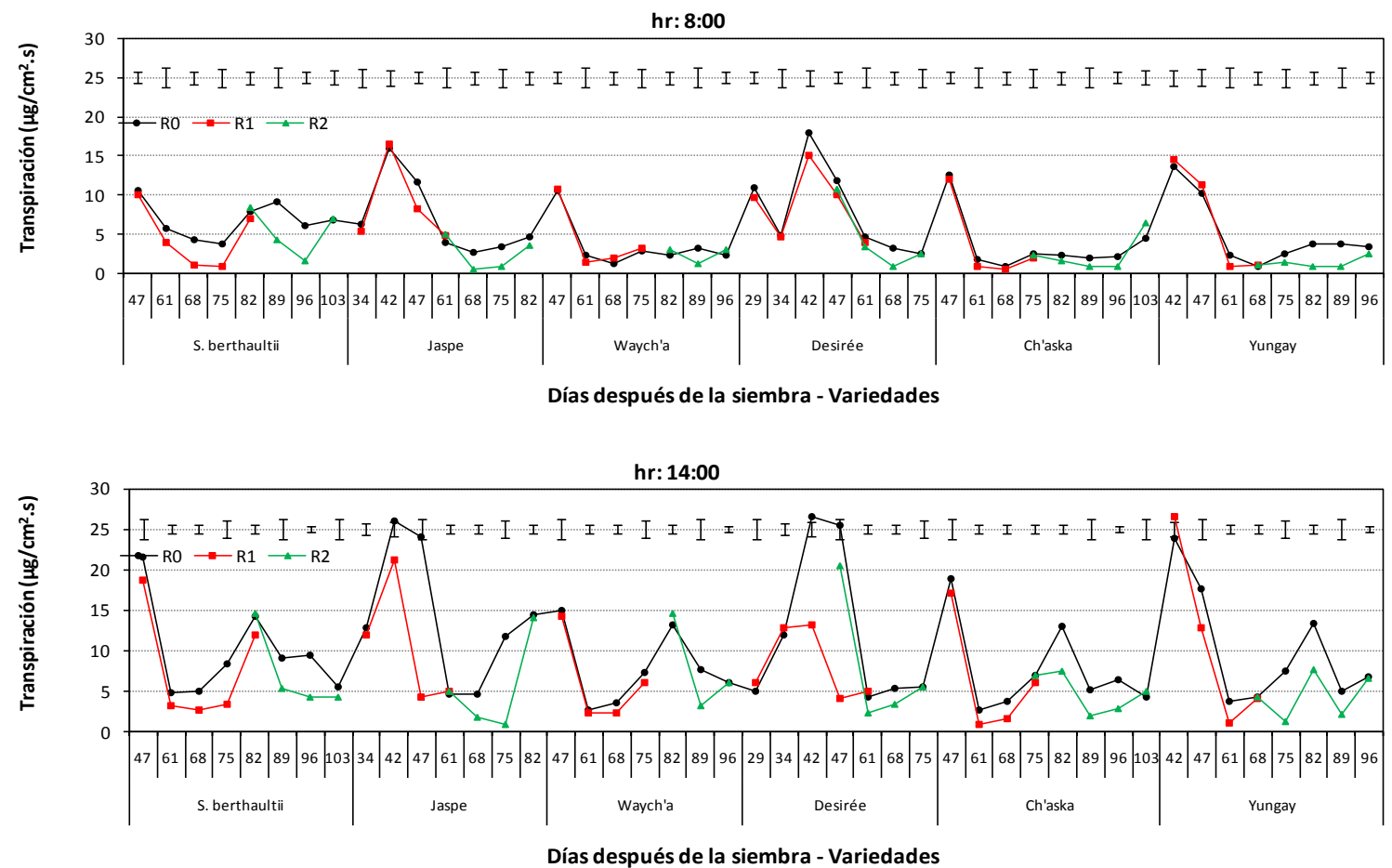

Figura 7. Variación de la Transpiración por efecto de la sequía en seis variedades de papa y en dos horarios de evaluación. Resultados del primer ensayo, donde: R0 = Riego normal; R1 = Sequía inicio tuberización y R2 = Sequía a un mes del inicio de la tuberización. Las barras en la parte superior denotan la Diferencia Mínima Significativa (DMS) para cada momento de evaluación ( $\mathrm{p}<0.05)$.

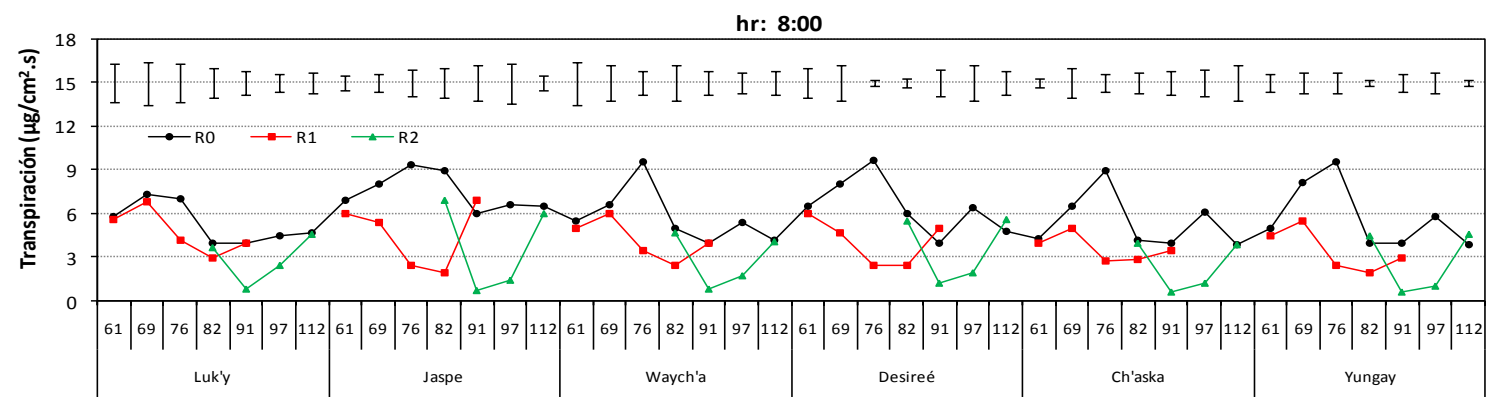

Días después de la siembra - Variedades

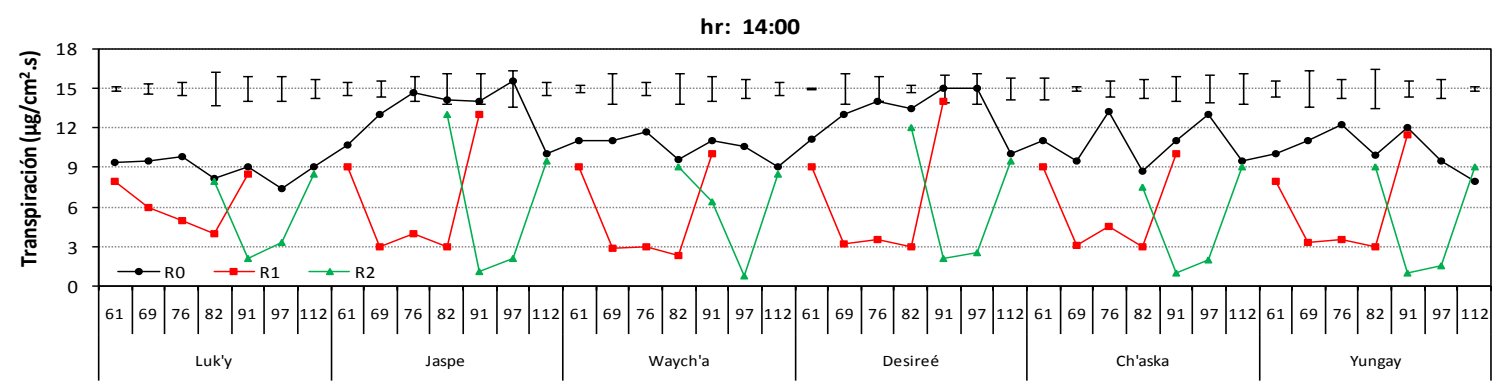

Días después de la siembra - Variedades

Figura 8. Variación de la Transpiración por efecto de la sequía en seis variedades de papa y en dos horarios de evaluación. Resultados del segundo ensayo, donde: R0 = Riego normal; R1 = Sequía temprana y R2 = Sequía tardía. Las barras en la parte superior denotan la Diferencia Mínima Significativa (DMS) para cada momento de evaluación $(\mathrm{p}<0.05)$. 


\section{ARTÍCULO DE INVESTIGACIÓN}

Revista Latinoamericana de la Papa 19 (2): 42-67 http://www.papaslatinas.org/revista.html

\section{Resistencia difusiva estomatal (RDE) vs Transpiración}

El análisis de regresión entre la RDE y la Transpiración en condiciones de riego normal (R0) (Figura 9) muestra una relación cuadrática inversa entre ambos (con un $\mathrm{R}^{2}$ próximo a 0.7 ), es decir existe mayor transpiración a menor RDE y viceversa, incrementándose la tasa de transpiración cuando los niveles de RDE se encuentran por debajo de $1 \mathrm{~s} / \mathrm{cm}$, especialmente a horas 14:00. Valladares

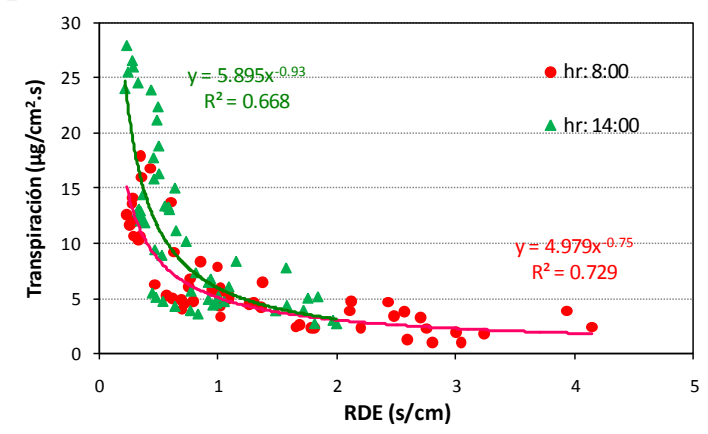

(2004) indica que existen dos mecanismos evitadores del estrés hídrico, uno que permite minimizar la pérdida de agua como: el cierre de estomas, la reducción de la transpiración, el aumento de la RDE, la presencia de hojas pequeñas, etc; y otro que busca maximizar la absorción de agua como el incremento del crecimiento radicular. El aumento de la RDE y la reducción de la transpiración son respuestas inmediatas de la planta que están relacionadas a través del cierre estomático.

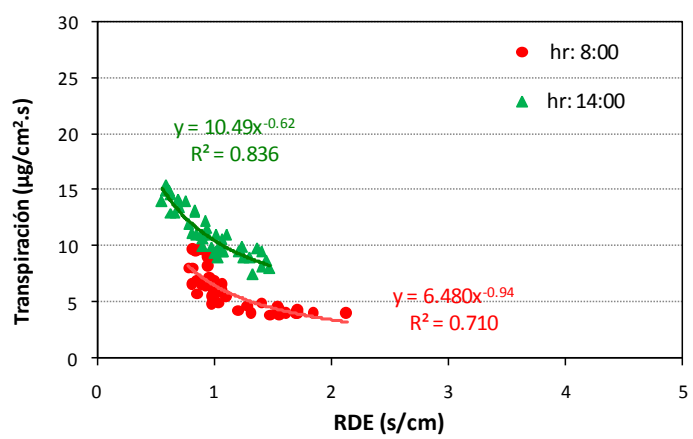

Figura 9. Análisis de regresión entre la Transpiración y la Resistencia Difusiva Estomatal (RDE) en dos horarios de evaluación y en condiciones de riego normal (R0). Resultados del primer y segundo ensayo respectivamente.

El análisis de regresión por variedad y en condiciones de riego normal (R0) que se presenta en la Figura 10 muestra a $S$. berthaultii y Desireé (líneas de color rojo y celeste de la izquierda respectivamente) difieren de las demás porque sus RDEs no suben mas allá de $1.5 \mathrm{~s} / \mathrm{cm}$ y mantienen tasas más altas de Transpiración. Por su parte Waych'a, Yungay y Chask'a (líneas de color negro, amarillo y verde de la izquierda) alcanzan RDEs altas (hasta 4 s/cm) y sus niveles de Transpiración son intermedias. Jaspe (línea lila de la izquierda) parece tener un comportamiento intermedio entre los anteriores, aunque en el segundo ensayo (línea lila de la derecha) se asemeja a Desireé. En general se puede indicar que $S$. berthaultii, Desireé y Jaspe mantienen niveles altos de Transpiración a bajos niveles de RDEs. Waych'a, Chask'a y Yungay mantienen niveles medios de Transpiración a niveles medios de RDEs. En el segundo ensayo se observa que Luk'y (línea de color rojo de la derecha) tiene un comportamiento muy diferente a las demás variedades, es decir una transpiración baja aun en condiciones de RDEs bajas. Este comportamiento diferente de Luk'y expresa que su capacidad de administración del agua es distinto al resto de las variedades. 

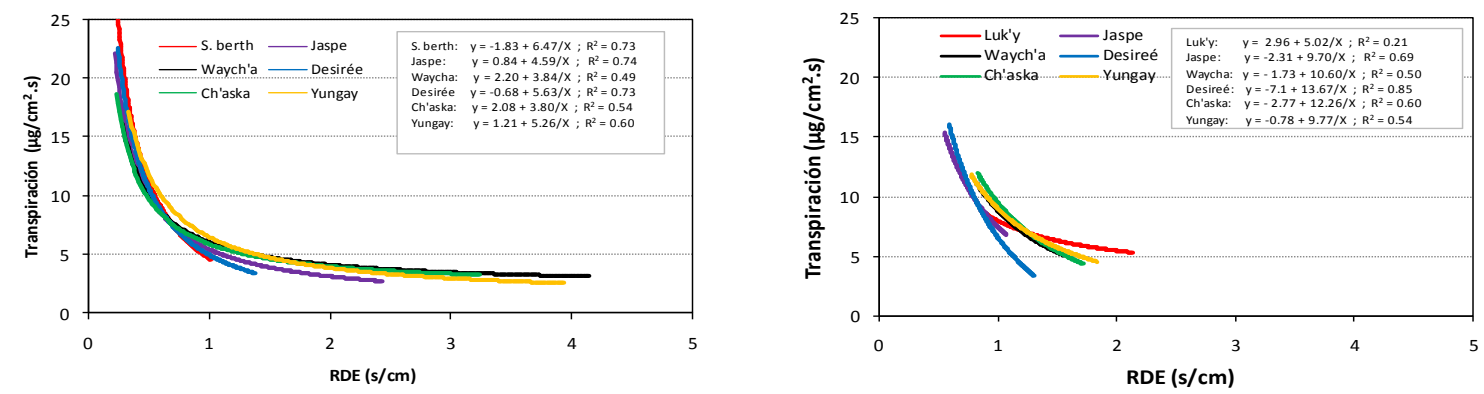

Figura 10. Análisis de regresión entre la Transpiración y la Resistencia Difusiva Estomatal (RDE) en seis variedades de papa y en condiciones de riego normal (R0). Resultados del primer y segundo ensayo respectivamente.
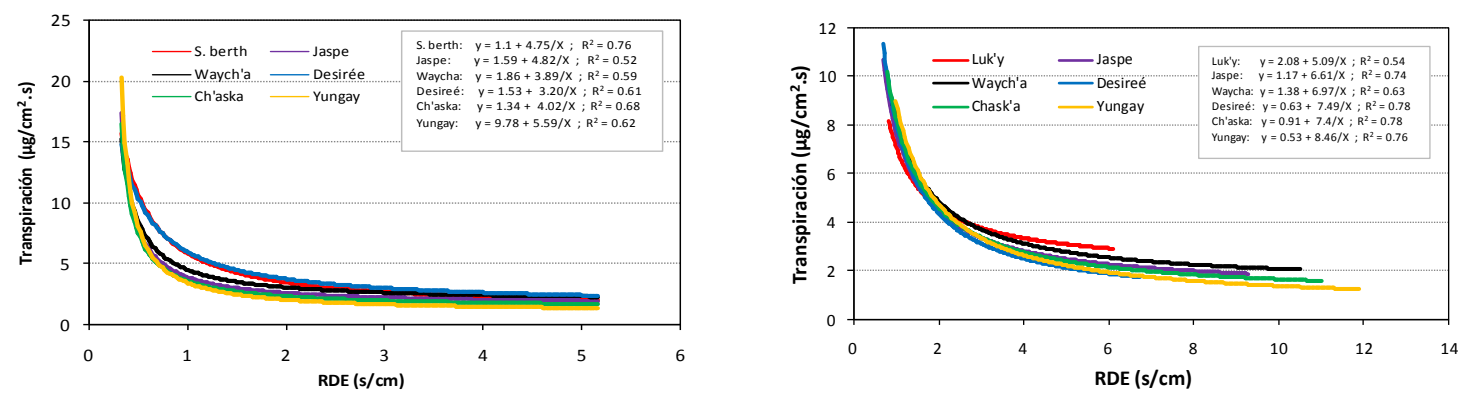

Figura 11. Análisis de regresión entre la Transpiración y la Resistencia Difusiva Estomatal (RDE) en seis variedades de papa y en condiciones de sequia. Resultados del primer y segundo ensayo respectivamente.

\section{Potencial Hídrico Foliar (PHF)}

Las Figuras 12 y 13 presentan la variación en el tiempo del PHF de seis variedades de papa en condiciones de riego normal R0 (plantas control) medidos en dos horarios extremos en cuanto a demanda evaporativa (6:30 y 12:00), de dos ensayos consecutivos respectivamente. Se observa que el PHF de todas las plantas varió de -2 a -8 bares, siendo mayor en las mañanas que en las tardes $(\mathrm{p}<0.05)$, comportamiento similar obtenido en la Resistencia Difusiva Estomatal (RDE) descrito en la Figura 1.

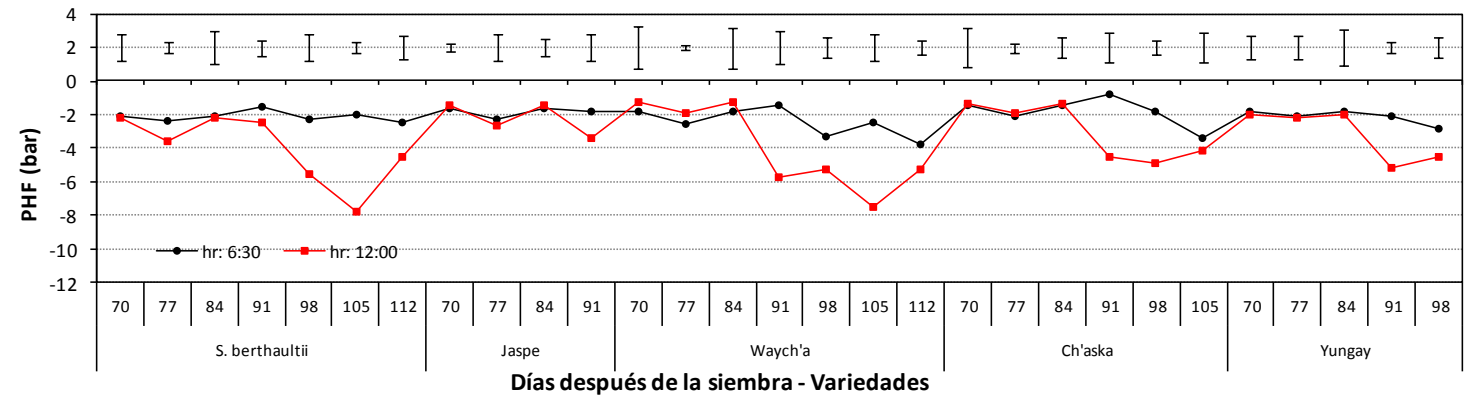

Figura 12. Variación del Potencial Hídrico Foliar (PHF) de cinco variedades de papa, en dos horarios de evaluación y bajo condiciones de riego normal (R0). Resultados del primer ensayo. Las barras en la parte superior denotan la Diferencia Mínima Significativa (DMS) para cada momento de evaluación $(\mathrm{p}<0.05)$. 


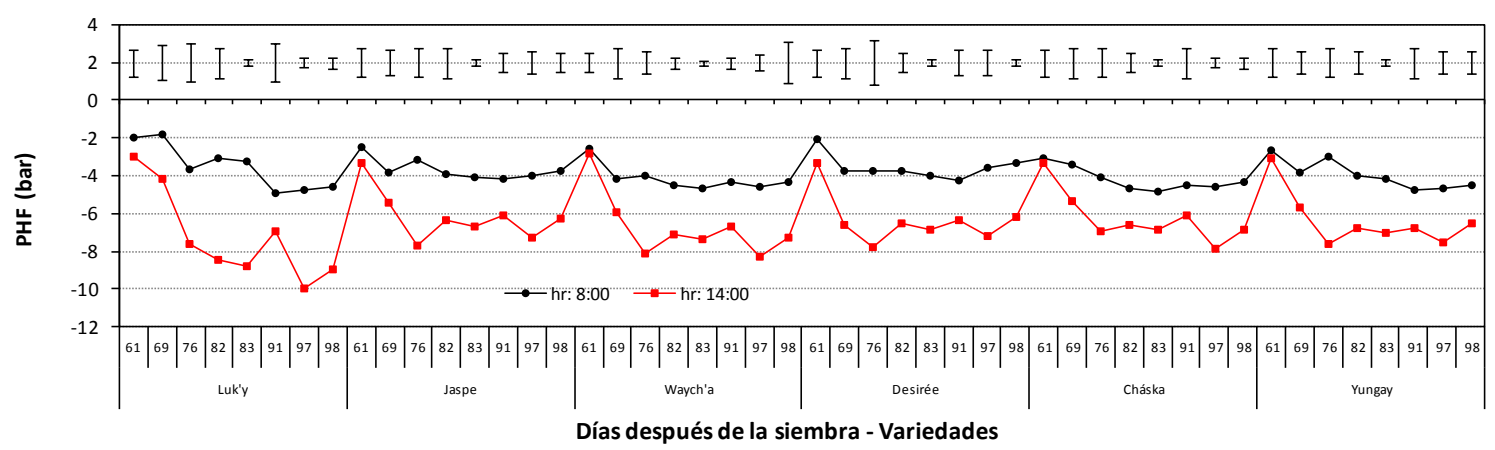

Figura 13. Variación del Potencial Hídrico Foliar (PHF) de seis variedades de papa, en dos horarios de evaluación y bajo condiciones de riego normal (R0). Resultados del segundo ensayo. Las barras en la parte superior denotan la Diferencia Mínima Significativa (DMS) para cada momento de evaluación $(\mathrm{p}<0.05)$.

En condiciones de sequía todas las variedades redujeron su PHF, unas más que otras $(\mathrm{p}<0.05)$. En el primer ensayo (Figura 14) se observa que en ambos horarios (6:30 y 12:00) Jaspe, Waych'a, Ch'aska y Yungay disminuyen su PHF en mayor proporción respecto de las plantas control (R0), por efecto de la sequía tardía (R2). S. berthaulti no parece disminuir substancialmente su PHF en condiciones de sequía $(p<0.05)$. En el segundo ensayo (Figura 15) la tendencia es similar, ambas sequias (R1 y R2) logran disminuir el PHF de las variedades y Luk'y no parece diferenciarse substancialmente del resto de las variedades. En condiciones de sequia no se observan diferencias entre los horarios 6:30 y 12:30. Trabajos en papa realizados por Jerez et al. (1993) demostraron que el PHF es más bajo a medio día e indican que a esta hora, el PHF de las plantas con sequia parcial no se diferenciaron significativamente de las plantas control contrariamente a las plantas con sequía severa que mantienen PHF más bajos que sus respectivas plantas controles. Tourneux, et al (2003) por su parte reportan que por efecto de la sequía, Solanum ajahuiri alcanzó los niveles más bajos de PHF (-2,3 MPa en 6h00, y -2,4 MPa a las 14h00) y Luky los niveles mas altos (-1,5 MPa a $6 \mathrm{~h} 00$ y $-1,6$ a $-1,7 \mathrm{MPa}$ a las 14h00).

A nivel celular, otra respuesta de resistencia a la sequía es el ajuste osmótico que consiste en una disminución del PHF lo cual tiene como consecuencia la entrada de agua y por tanto, no se presenta una disminución en el turgor o en la productividad fotosintetica. El ajuste osmótico se da en las plantas a través de la biosintesis de osmolitos orgánicos de bajo peso molecular y por la acumulación de iones, fundamentalmente $\mathrm{K}+$ (Cushman, 2001). 

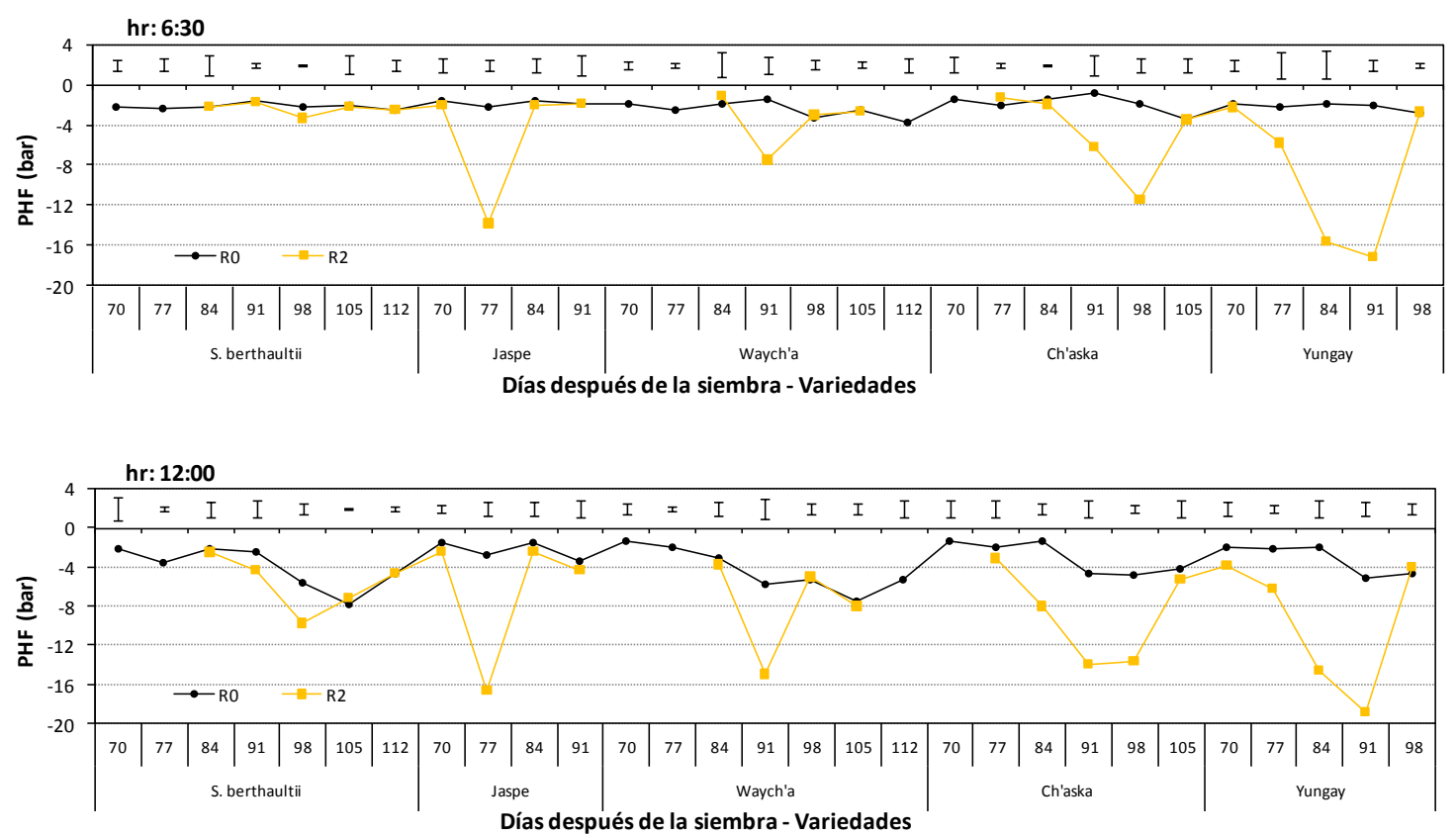

Figura 14. Variación del Potencial Hídrico Foliar (PHF) por efecto de la sequía en seis variedades de papa y en dos horarios de evaluación. Resultados del primer ensayo, donde: R0 = Riego normal; R1 = Sequía inicio tuberización y R2 = Sequía a un mes del inicio de la tuberización. Las barras en la parte superior denotan la Diferencia Mínima Significativa (DMS) para cada momento de evaluación ( $\mathrm{p}<0.05)$.

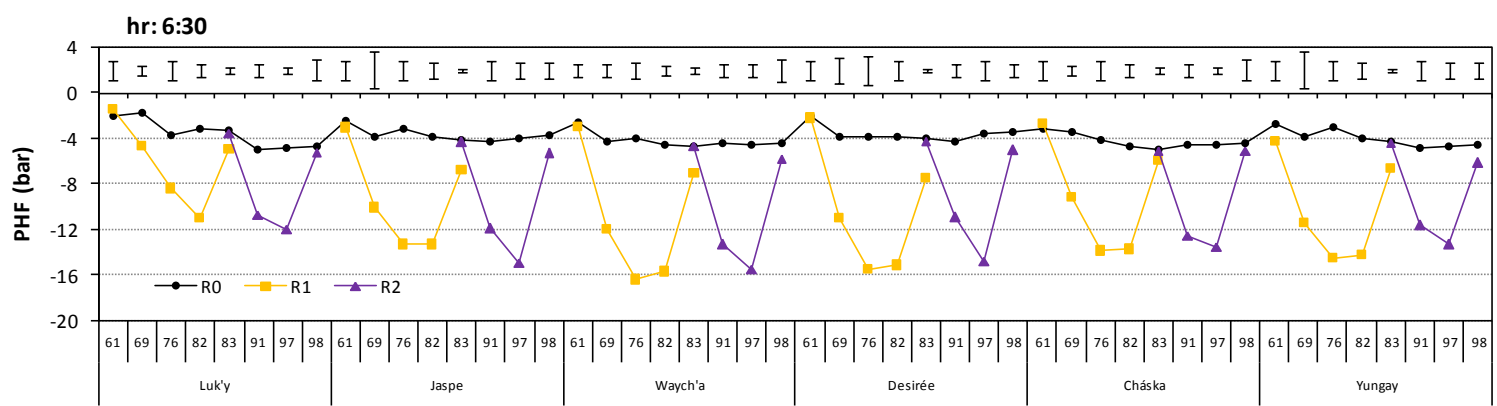

Días después de la siembra - Variedades

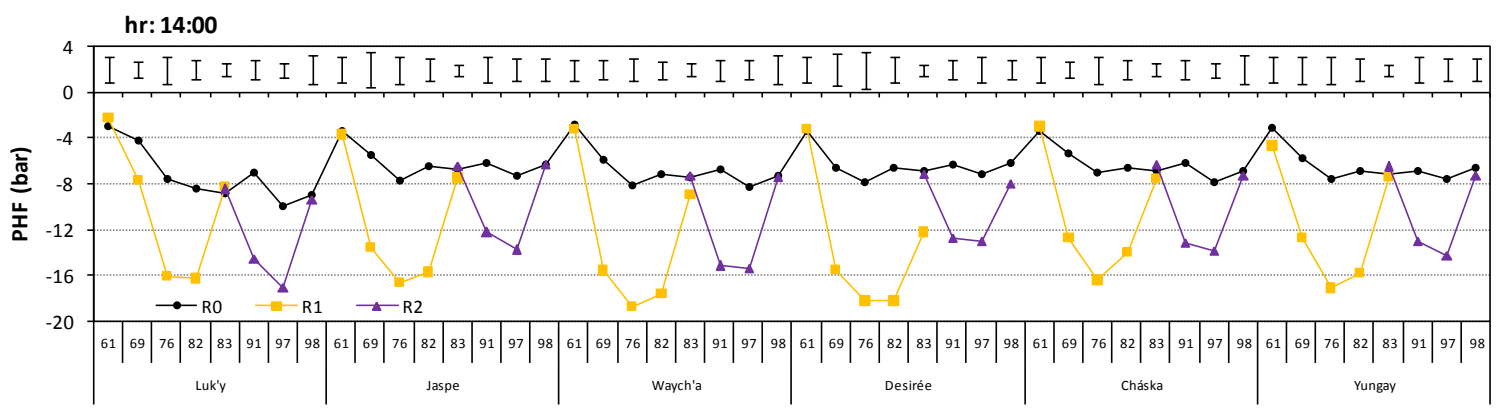

Días después de la siembra - Variedades

Figura 15. Variación del Potencial Hídrico Foliar (PHF) por efecto de la sequía en seis variedades de papa y en dos horarios de evaluación. Resultados del segundo ensayo, donde: $\mathrm{R} 0$ = Riego normal; $\mathrm{R} 1$ = Sequía temprana y R2 = Sequía tardía. Las barras en la parte superior denotan la Diferencia Mínima Significativa (DMS) para cada momento de evaluación ( $\mathrm{p}<0.05)$. 


\section{E. Potencial Hídrico Foliar (PHF) vs Resistencia Difusiva Estomatal (RDE)}

El análisis de regresión entre el PHF y la RDE en condiciones de riego normal (R0) (Figura 16) muestra que ambas variables no están claramente asociadas en ninguno de los horarios de evaluación y en ninguna de las variedades estudiadas. Tourneux et al. (2003) tampoco encontraron diferencia entre los genotipos de papa en la relación RDE y PHF. El mayor valor de PHF que encontraron fue cerca de -1,0 MPa, el cual es alto en comparación con los de otras especies, que van desde $-0.8 \mathrm{MPa}$ (en habas) a -2.8 MPa (en algodón), (Turner, 1979).
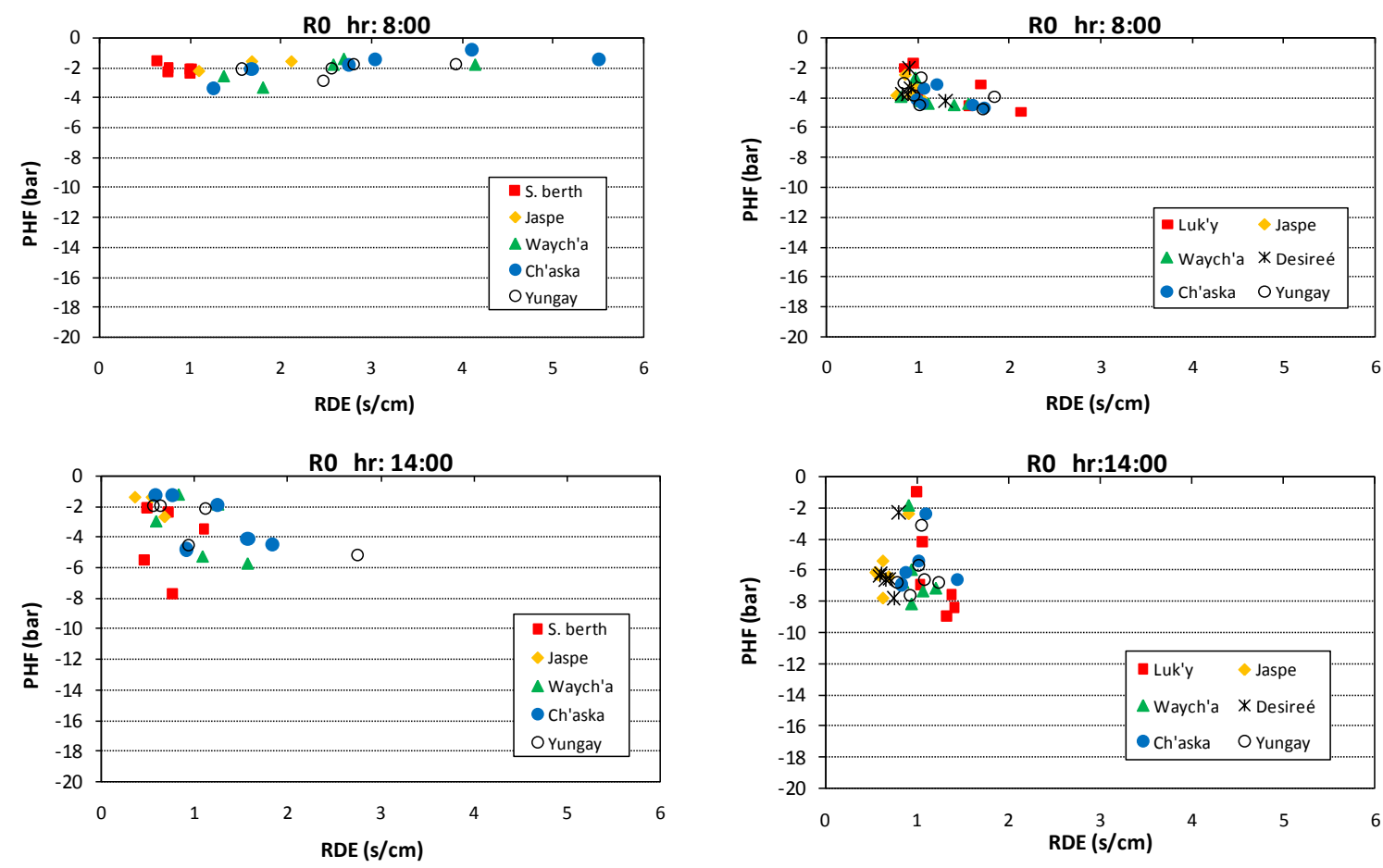

Figura 16. Análisis de regresión entre el Potencial Hídrico Foliar (PHF) y la Resistencia Difusiva Estomatal (RDE) en dos horarios de evaluación y en condiciones de riego normal (R0). Resultados del primer y segundo ensayo respectivamente.

El análisis de regresión entre el PHF y la RDE en condiciones de sequia (Figura 17) muestra que ambas variables están relacionadas a través de una función cuadrática inversa con un coeficiente $\mathrm{R}^{2}$ mayor al $70 \%$. Esto significa que en condiciones de sequía a medida que aumenta la RDE, el PHF de las plantas disminuye y viceversa. Si bien esta asociación es alta a nivel de la población de la variedades estudiadas, también se observan diferencias entre variedades donde $S$. berthaulti en el primer ensayo (puntos rojos de las dos sub figuras superiores) mantiene solo altos niveles de
PHF a una baja RDE. En el segundo ensayo Luk'y (puntos rojos de las cuatro sub figuras inferiores) también se diferencia del resto. Tourneux et al., (2003) reportan que por encima de un valor umbral de PHF (aproximadamente -1,0 $\mathrm{MPa})$ la RDE en papa osciló de 1 a 5 s.cm1 , excepto en la variedad Luk'y. Indican que por debajo de este umbral, las RDEs aumentaron rápidamente, sin diferencias significativas entre los genotipos. En el rango de 0 a $-1,0 \mathrm{MPa}$, algunos de los valores de RDEs de Luk'y eran mucho más altos que en los otros genotipos. 

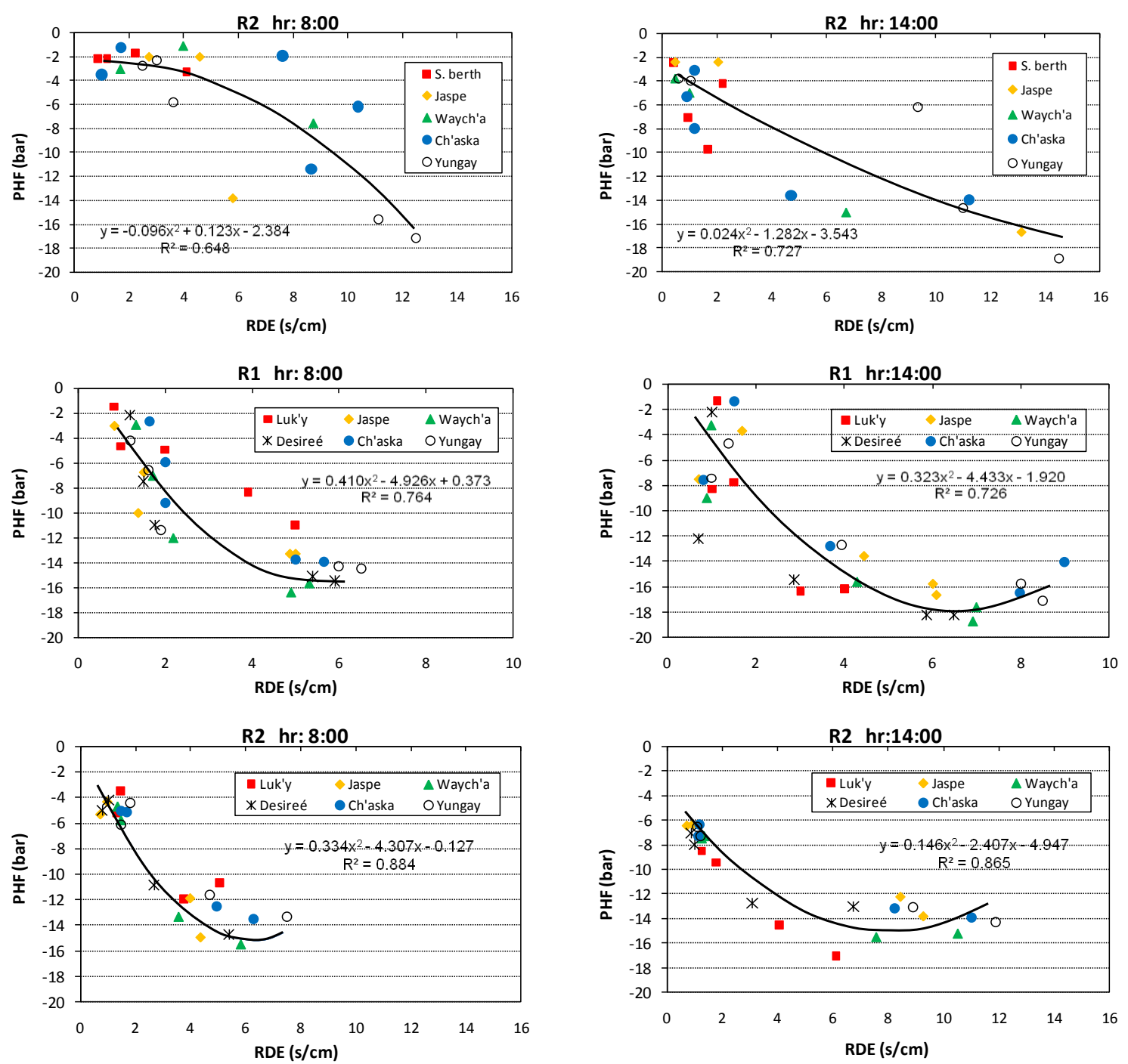

Figura 17. Análisis de regresión entre el Potencial Hídrico Foliar (PHF) y la Resistencia Difusiva Estomatal (RDE) en seis variedades de papa y en condiciones de sequia. Resultados del primer y segundo ensayo respectivamente. Donde R0 = Riego normal; R1 = Sequía temprana y R2 = Sequía tardía.

Jerez et al., (1993), encontraros diferencias en la conductancia estomática $($ Conductancia $=1 / \mathrm{RDE})$ entre variedades de papa en condiciones de una sequía parcial arguyendo que las variedades de menor conductancia tienen que realizar un mayor control de sus estomas para mantener PHF elevados. Al haber encontrado valores bajos de conductancia estomática en condiciones de una sequia severa que son coincidentes con los valores bajos de PHF, les permite señalar la estrecha asociación entre ambas variables. También indican que algunas variedades como Red Pontiac que aún con los estomas cerrados continúan disminuyendo su PHF lo que según ellos pudo deberse al efecto que la condición de estrés pudo haber provocado en la conductividad de las raíces.

En un estudio de once especies perennes mediterráneas, la única tendencia clara que se encontró es el aumento de la conductancia estomática (Conductancia $=$ 1 / RDE) con la disminución del PHF mínimo, es decir, las especies que sufrían un mayor estrés hídrico durante la sequía fueron aquellas que mostraron una mayor conductancia estomática (Terradas, 2001). 


\section{F. Contenido Relativo de Agua Foliar (CRAF)}

La Figura 18 presenta la variación en el tiempo del CRAF por efecto de la sequía en seis variedades de papa. Como se observa, todas las variedades redujeron su CRAF por efecto de la sequía, unas más que otras. Entre todas, destaca la variedad Luk'y con una menor reducción de su
CRAF. En condiciones similares, Tourneux et al. (2003) encontraron un similar comportamiento de Luk'y e indican que la recuperación de las plantas fue mucho más rápida en la mañana que en la tarde debido a la incapacidad de las plantas para mantener un contenido alto de agua en las hojas durante la tarde, cuando la demanda evaporativa estaba en su máximo.

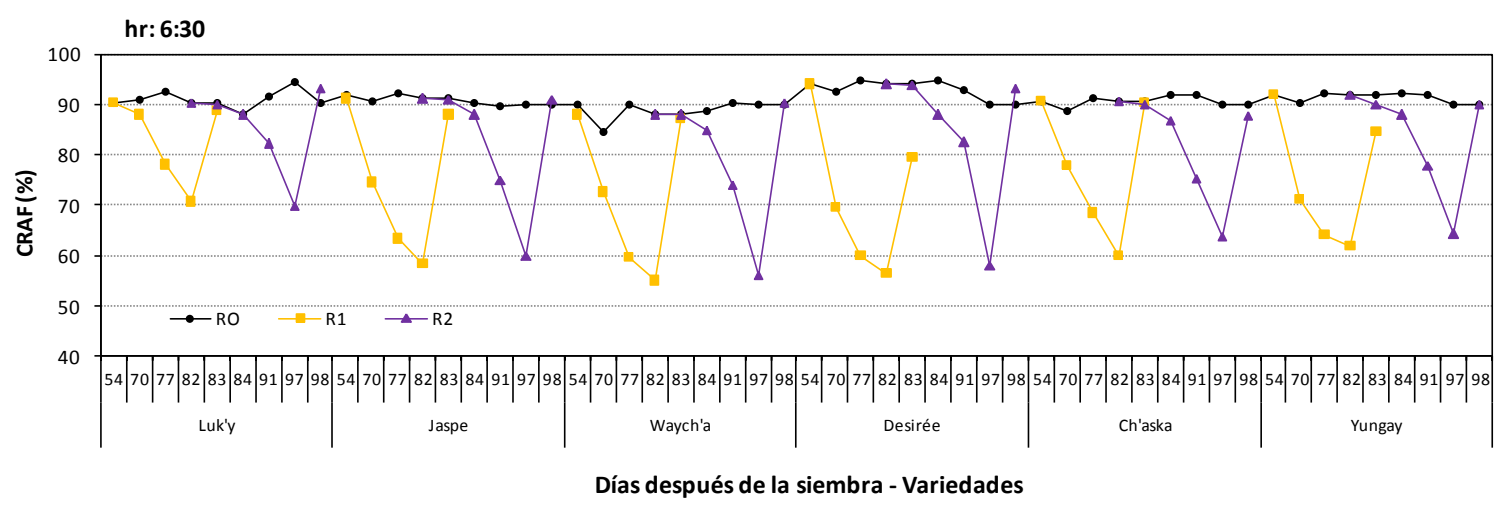

Figura 18. Variación del Contenido Relativo de Agua Foliar (CRAF) por efecto de la sequía en seis variedades de papa. Resultados del segundo ensayo, donde: R0 = Riego normal; R1 = Sequía temprana y R2 = Sequía tardía.

El cultivo de papa muestra una gran variabilidad en su comportamiento entre uno y otro año siendo el CRAF es un indicador es muy sensible a los cambios ambientales, sobre todo de temperatura y humedad relativa (Jerez et al., 1991). El CRAF alcanza mayores valores con la edad de la planta, lo que está dado por una marcada reducción en el uso del agua, debido principalmente a la baja tasa de transpiración y a la pérdida del follaje funcional. El CRAF también está influido por la radiación y el déficit de presión de vapor (Jerez et al., 1993).

\section{G. Contenido Relativo de Agua Foliar (CRAF) vs Potencial Hídrico Foliar (PHF)}

La Figura 19 muestra que no existe asociación entre el PHF y el CRAF en condiciones de riego normal en ninguna de las variedades estudiadas. Este comportamiento es similar al análisis de regresión entre el PHF y la RDE que se muestra en la Figura 16.

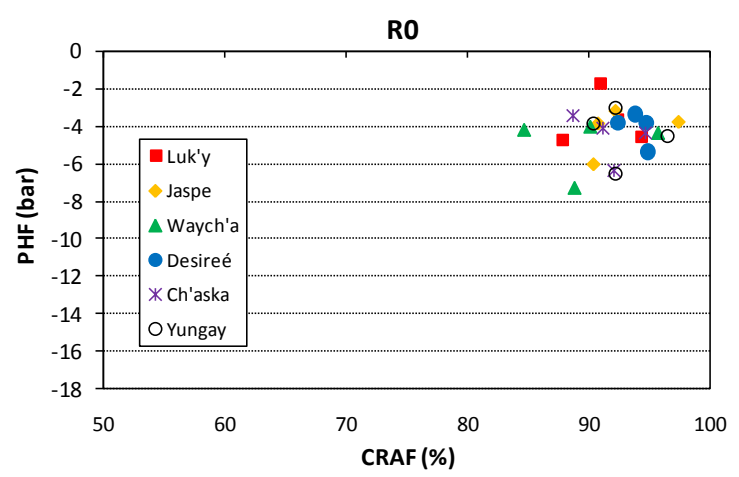

Figura 19. Análisis de regresión entre el Potencial Hídrico Foliar (PHF) y el Contenido Relativo de Agua Foliar (CRAF) de seis variedades de papa evaluado en condiciones de riego normal (R0) y a horas 6:30 am. Resultados del segundo ensayo.

La Figura 20 muestra que existe una asociación lineal entre el PHF y el CRAF con un coeficiente $\mathrm{R}^{2}$ mayor al $85 \%$ en condiciones de sequía, es decir en 
condiciones de sequia a mayor PHF existe mayor CRAF, pero no se observan grandes diferencias genotípicas. Tourneux, et al (2003), también encontraron una relación directa entre el PHF y el CRAF la cual no está afectada por el genotipo de papa, el momento de medición, el tratamiento de sequía y por lo tanto esta relación no puede ser utilizada para desarrollar nuevos genotipos de papa. Vos et al. (1988) tampoco encontraron efecto del genotipo sobre la relación entre el PHF y el CRAF, e indican que la ausencia de diferencias genotípicas podría indicar una ausencia de ajuste osmótico en los genotipos de papa.
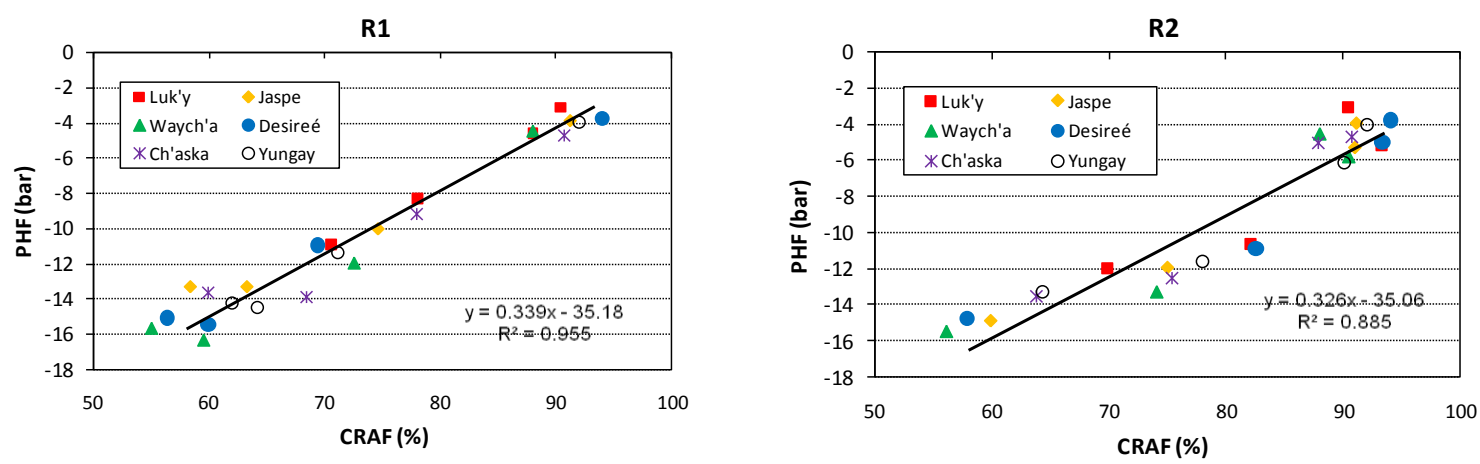

Figura 20. Análisis de regresión entre el Potencial Hídrico Foliar (PHF) y el Contenido Relativo de Agua Foliar (CRAF) de seis variedades de papa, evaluado en condiciones de sequía y a horas 6:30 am. Resultados del segundo ensayo, donde R1 = Sequía temprana y R2 = Sequía tardía.

\section{H. Rendimiento de tubérculos}

Como se ve en la Figura 21, en ambos ensayos en condiciones de riego normal (R0) existe, diferencias marcadas en el rendimiento entre variedades, destacando las variedades Yungay y Ch'aska seguidos de Jaspe, Desirée y Waych'a y finalmente S. berthaultii y Luk'y. El análisis del rendimiento relativo de la Figura 21 muestra diferencias entre la sequía temprana $\mathrm{R} 1$ y la sequía tardía $\mathrm{R} 2$ según sea la variedad. En el primer ensayo Desirée, S. berthaultii y Waych'a son las más afectadas por la sequía temprana R1 que por la sequía tardía R2. En Jaspe, Ch'aska y Yungay el efecto de ambas sequías es similar. En $S$. berthaultii y Waych'a no se observa un efecto marcado de la sequía tardía R2. En el segundo ensayo las tendencias son similares, con la diferencia de que en Waych'a los efectos de ambas sequías son similares y menos marcadas que en el primer ensayo y en Jaspe, Ch'aska y Yungay el efecto de la sequía tardía R2 es de menor grado que en el primer ensayo. En la variedad Luk'y, ambas sequías tuvieron el mismo efecto. 
Revista Latinoamericana de la Papa 19 (2): 42-67

http://www.papaslatinas.org/revista.html
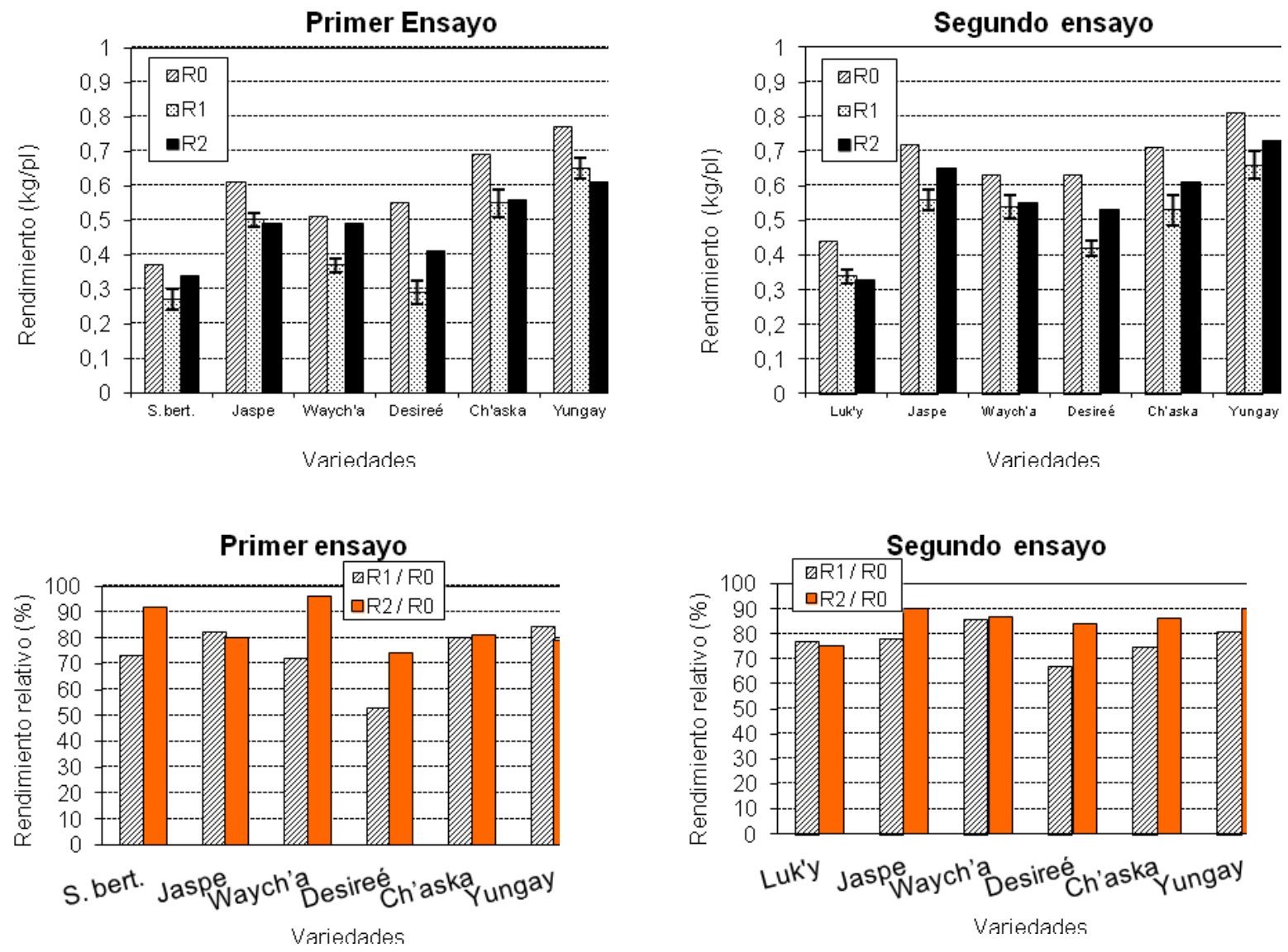

Figura 21. Efecto de la sequía en el rendimiento total y rendimiento relativo de seis variedades de papa evaluados en dos años consecutivos, donde: $\mathrm{R} 0=$ Riego normal; $\mathrm{R} 1$ = Sequía temprana y R2 = Sequía tardía. La barra (s.e.) solo permite la comparación estadística entre tratamientos dentro de cada variedad.

\section{Variables fisiológicas vs rendimiento}

En las Tablas 2 y 3 se muestra la correlación entre las variables fisiológicas $\mathrm{y}$ el rendimiento en condiciones de riego normal (R0) y sequía (R1 y $\mathrm{R} 2$ ) correspondiente a dos ensayos consecutivos respectivamente. En ambos se observa claramente que la RDE, la Transpiración y el PHF, están correlacionadas con el rendimiento especialmente cuando estas fueron evaluadas en condiciones de una sequia tardía (R2) en el primer ensayo y de una sequia temprana (R1) en el segundo ensayo. Tourneux et al. (2003) también encontraron correlación entre el PHF evaluado a horas 14:00 $(\mathrm{P}<0,01)$ y el rendimiento. La relación entre la RDE y el rendimiento de la papa fue reportado con mucha variación de un año a otro (Dwelle et al., 1981). Candilo et al. (1995) y Spitters et al. (1990) señalan la complejidad de los procesos involucrados en el rendimiento de la papa y la de correlación entre este y los parámetros fisiológicos.

La falta de una alta correlación se atribuye principalmente a la fuerte interacción genotipo-ambiente en la tolerancia a la sequía y al contraste entre las respuestas fisiológicas rápidas (como la resistencia de los estomas, potencial hídrico foliar, etc.) y las respuestas lentas y acumuladas como el rendimiento, la materia seca, etc. El grado de influencia de un carácter en el rendimiento depende de la escala de tiempo y principalmente del nivel de organización (Molécula, célula, órgano, planta, cultivo) en el que el carácter se 
expresa. Cuanto más cerca de un carácter esta el nivel de organización del cultivo, mayor influencia tendrá en la productividad. Es por esto por ejemplo que el área foliar debería ser un carácter más importante que la apertura estomática
(Richards, 1996). Los caracteres que confieren tolerancia a la sequía son sutiles, dependerá del tipo de sequía, y con frecuencia no tienen directa conexión con las relaciones hídricas de plantas (Passioura et al., 1996).

Tabla 2. Correlación (r) entre el rendimiento y las variables fisiológicas. Primer ensayo.

\begin{tabular}{|c|c|c|c|c|c|c|c|}
\hline $\begin{array}{l}\text { Variable } \\
\text { fisiológica }\end{array}$ & $\begin{array}{c}\text { Trat. } \\
\text { hídrico }\end{array}$ & $\begin{array}{c}\text { Hora de } \\
\text { evaluación }\end{array}$ & Rend RO & Rend R1 & Rend R2 & $\begin{array}{c}\text { Rend. } \\
\text { Relativo } \\
\text { R1/R0 }\end{array}$ & $\begin{array}{c}\text { Rend. } \\
\text { Relativo } \\
\text { R2/R0 }\end{array}$ \\
\hline RDE & R0 & $8 \mathrm{am}$ & 0.58 & 0.63 & 0.77 & 0.50 & 0.15 \\
\hline RDE & $\mathrm{R} 1$ & $8 \mathrm{am}$ & 0.28 & 0.41 & 0.45 & 0.48 & 0.31 \\
\hline RDE & $\mathrm{R} 2$ & $8 \mathrm{am}$ & 0.78 & 0.87 & 0.93 & 0.71 & 0.01 \\
\hline RDE & R0 & $14: 00 \mathrm{pm}$ & 0.45 & 0.46 & 0.65 & 0.30 & 0.25 \\
\hline RDE & $\mathrm{R} 1$ & $14: 00 \mathrm{pm}$ & 0.08 & -0.01 & 0.05 & -0.11 & -0.13 \\
\hline $\mathrm{RDE}$ & $\mathrm{R} 2$ & $14: 00 \mathrm{pm}$ & 0.86 & 0.95 & 0.89 & 0.75 & -0.29 \\
\hline Transpiración & R0 & $8 \mathrm{am}$ & -0.34 & -0.47 & -0.62 & -0.51 & -0.46 \\
\hline Transpiración & $\mathrm{R} 1$ & $8 \mathrm{am}$ & 0.23 & 0.05 & -0.03 & -0.26 & -0.71 \\
\hline Transpiración & $\mathrm{R} 2$ & $8 \mathrm{am}$ & -0.85 & -0.89 & -0.96 & -0.65 & 0.15 \\
\hline Transpiración & $\mathrm{R} 0$ & $14: 00 \mathrm{pm}$ & 0.02 & -0.04 & -0.21 & -0.13 & -0.55 \\
\hline Transpiración & $\mathrm{R} 1$ & $14: 00 \mathrm{pm}$ & 0.42 & 0.47 & 0.26 & 0.35 & -0.51 \\
\hline Transpiración & $\mathrm{R} 2$ & $14: 00 \mathrm{pm}$ & -0.80 & -0.92 & -0.76 & -0.81 & 0.42 \\
\hline PHF & R0 & $8 \mathrm{am}$ & 0.38 & 0.42 & 0.18 & 0.65 & -0.78 \\
\hline PHF & $\mathrm{R} 2$ & 8 am & -0.90 & -0.93 & -0.86 & -0.85 & 0.74 \\
\hline PHF & R0 & $14: 00 \mathrm{pm}$ & 0.60 & 0.65 & 0.44 & 0.85 & -0.89 \\
\hline PHF & $\mathrm{R} 2$ & $14: 00 \mathrm{pm}$ & -0.84 & -0.79 & -0.92 & -0.48 & 0.40 \\
\hline
\end{tabular}

$\mathrm{RDE}=$ Resistencia Difusiva Estomatal

PHF = Potencial Hídrico Foliar

$\mathrm{R} 0$ = Riego normal; R1 = Sequía temprana y R2 = Sequía tardía 
Tabla 3. Correlación (r) entre el rendimiento y las variables fisiológicas. Segundo ensayo.

\begin{tabular}{lclccccc}
\hline $\begin{array}{l}\text { Variable } \\
\text { fisiológica }\end{array}$ & $\begin{array}{c}\text { Trat. } \\
\text { hídrico }\end{array}$ & $\begin{array}{c}\text { Hora de } \\
\text { evaluación }\end{array}$ & Rend Ro & Rend R1 & Rend R2 & $\begin{array}{c}\text { Rend. } \\
\text { Relativo } \\
\text { R1/R0 }\end{array}$ & $\begin{array}{c}\text { Rend. } \\
\text { Relativo } \\
\text { R2/R0 }\end{array}$ \\
\hline RDE & R0 & $8 \mathrm{am}$ & -0.24 & -0.06 & -0.28 & 0.37 & -0.43 \\
RDE & $\mathrm{R} 1$ & $8 \mathrm{am}$ & $\mathbf{0 . 7 4}$ & 0.65 & $\mathbf{0 . 7 0}$ & 0.01 & 0.59 \\
RDE & $\mathrm{R} 2$ & $8 \mathrm{am}$ & 0.46 & 0.57 & 0.43 & 0.41 & 0.24 \\
RDE & $\mathrm{R} 0$ & $14: 00 \mathrm{pm}$ & -0.32 & -0.09 & -0.34 & 0.46 & -0.46 \\
RDE & $\mathrm{R} 1$ & $14: 00 \mathrm{pm}$ & $\mathbf{0 . 9 1}$ & $\mathbf{0 . 8 9}$ & $\mathbf{0 . 9 0}$ & 0.26 & $\mathbf{0 . 8 7}$ \\
RDE & $\mathrm{R} 2$ & $14: 00 \mathrm{pm}$ & $\mathbf{0 . 7 5}$ & $\mathbf{0 . 9 0}$ & $\mathbf{0 . 7 6}$ & 0.68 & $\mathbf{0 . 7 3}$ \\
Transpiración & $\mathrm{R} 0$ & $8 \mathrm{am}$ & 0.33 & 0.20 & 0.37 & -0.21 & 0.50 \\
Transpiración & $\mathrm{R} 1$ & $8 \mathrm{am}$ & $\mathbf{- 0 . 7 4}$ & $\mathbf{- 0 . 6 6}$ & -0.69 & -0.03 & -0.53 \\
Transpiración & $\mathrm{R} 2$ & $8 \mathrm{am}$ & -0.05 & -0.19 & -0.01 & -0.39 & 0.13 \\
Transpiración & $\mathrm{R} 0$ & $14: 00 \mathrm{pm}$ & 0.42 & 0.18 & 0.44 & -0.48 & 0.54 \\
Transpiración & $\mathrm{R} 1$ & $14: 00 \mathrm{pm}$ & -0.25 & -0.51 & -0.27 & $\mathbf{- 0 . 8 1}$ & -0.31 \\
Transpiración & $\mathrm{R} 2$ & $14: 00 \mathrm{pm}$ & -0.15 & -0.21 & -0.10 & -0.19 & 0.12 \\
PHF & $\mathrm{R} 0$ & $8 \mathrm{am}$ & -0.50 & -0.62 & -0.49 & -0.53 & -0.50 \\
PHF & $\mathrm{R} 1$ & $8 \mathrm{am}$ & $\mathbf{- 0 . 7 1}$ & $\mathbf{- 0 . 6 6}$ & $\mathbf{- 0 . 7 2}$ & -0.15 & $\mathbf{- 0 . 8 1}$ \\
PHF & $\mathrm{R} 2$ & $8 \mathrm{am}$ & -0.56 & -0.64 & -0.59 & -0.49 & $-\mathbf{- 0 . 7 6}$ \\
PHF & $\mathrm{R} 0$ & $14: 00 \mathrm{pm}$ & $\mathbf{0 . 8 5}$ & 0.64 & $\mathbf{0 . 8 4}$ & -0.24 & $\mathbf{0 . 8 4}$ \\
PHF & $\mathrm{R} 1$ & $14: 00 \mathrm{pm}$ & -0.22 & -0.12 & -0.23 & 0.16 & -0.38 \\
PHF & $\mathrm{R} 2$ & $14: 00 \mathrm{pm}$ & $\mathbf{0 . 8 5}$ & 0.63 & $\mathbf{0 . 8 4}$ & -0.28 & $\mathbf{0 . 8 2}$ \\
CRAF & $\mathrm{R} 1$ & $6: 30 \mathrm{am}$ & 0.30 & 0.00 & 0.27 & $\mathbf{- 0 . 7 7}$ & 0.15 \\
CRAF & $\mathrm{R} 2$ & $6: 30 \mathrm{am}$ & -0.59 & -0.50 & -0.60 & 0.00 & $\mathbf{- 0 . 7 3}$ \\
CRAF & $\mathrm{R} 3$ & $6: 30 \mathrm{am}$ & -0.49 & -0.55 & -0.52 & -0.42 & -0.69 \\
\hline Nivel de significacín $5 \%$ & & & & & & &
\end{tabular}

Nivel de significación 5\%

RDE $=$ Resistencia Difusiva Estomatal

PHF $=$ Potencial Hídrico Foliar

CRAF $=$ Contenido Relativo de Agua Foliar

$\mathrm{R} 0$ = Riego normal; $\mathrm{R} 1$ = Sequía temprana y R2 = Sequía tardía.

\section{Conclusiones}

Se ha evidenciado que los mecanismos fisiológicos: Resistencia Difusiva Estomatal (RDE), Transpiración, Potencial Hídrico Foliar (PHF) y Contenido Relativo de Agua Foliar (CRAF), son diferentes entre una y otra variedad de papa.

La mayor RDE, mayor PHF y menor Transpiración que se presentó en horas de menor demanda evaporativa del ambiente (8:00) y la menor RDE, menor PHF y mayor Transpiración que se presentó en horas de mayor demanda evaporativa (14:00), demuestran que en condiciones de buena humedad en el suelo, la mayoría de las variedades de papa no se limitan en la pérdida de agua a través de sus hojas, salvo la especie $S$. berthaultii que parece escapar a esta aseveración.
En condiciones de buena humedad en el suelo, Luk'y presenta baja tasa de transpiración lo que demuestra que su capacidad de regulación del agua es diferente al resto de las variedades.

Existe una relación inversa entre la RDE y la Transpiración. Por debajo de $1 \mathrm{~s} / \mathrm{cm}$ de RDE el incremento de la tasa de transpiración es substancial, especialmente a horas 14:00. Solo Luk'y escapa a esta aseveración porque mantiene una tasa de transpiración baja aun en condiciones de RDEs bajas, lo que muestra que su capacidad de administración del agua es distinto al resto de las variedades.

En condiciones favorables de humedad en el suelo, no parece existir relación entre el PHF y la RDE, tampoco entre el PHF y el CRAF. Esta asociación se hace evidente 
recién en condiciones de sequía, es decir en el primer caso a medida que aumenta la RDE, el PHF tiende a disminuir y en el segundo caso a mayor PHF el CRAF también es mayor, aunque no se evidencian grandes diferencias genotípicas, salvo el de $S$. berthaultii que mantiene altos niveles de PHF a una baja RDE.

La sequía redujo el CRAF de todas las variedades y se evidencia diferencias entre ellas. Destaca nuevamente Luk'y como la que reduce en menor medida su CRAF. Esta misma variedad en condiciones de sequía se diferencia del resto porque mantiene bajos niveles de Transpiración aun con una RDE baja. Este comportamiento expresa nuevamente que su capacidad de regulación del agua es distinta al resto de las variedades. Estudios anteriores demostraron que esta variedad amarga en condiciones de sequía mantiene abierto sus estomas aún en condiciones de PHF bajos (-15 bares) en relación a las variedades dulces que lo cierran a -12 bares.

Los mecanismos fisiológicos mas asociados con el rendimiento del cultivo de papa son la RDE, la Transpiración y el PHF.

\section{Conflictos de intereses}

Los autores declaran no tener conflictos con la publicación de este trabajo de investigación.

\section{Referencias citadas}

Berrocal, L.O. 1998. Elasticidad. Tercera edición. Ingenieria Industrial. S.A. Mcgraww Hill. Interamericana España. p 9.

Boyer, J. S. 1996. Advances in drought tolerance in plants. Advances in Agronomy. Academic Press.

Candilo, M.; Ruaro, G.; Marino, A.; Ranalli, P. 1995. Assessment of potato (Solanum tuberosum L.) in clones under different soil water availability conditions, Rev. Agron. 29 557-566.
Chaves, M.M.; Maroco, J.P.; Pereira, J.S. 2003. Understanding plant responses to drought: from genes to the whole plant. Functional Plant Biology 30: 239-264.

Cushman, J.C. 2001. Osmoregulation in plants: implications for agriculture. Amer. Zool. 41: 758-769.

Deblonde, P.M.; Ledent, J.F. 2001. Effects of moderate drought conditions on green leaf number, stem height, leaf length and tuber yield of potato cultivars, Eur. J. Agron. 14: 31-41.

Dwelle, R.B.; Harley, P.J.; Pavek, J.J. 1983. Photosynthesis and stomatal conductance of potato clones (Solanum tuberosum L.), Plant Physiol. 72: 172-176.

Duan, B.; Li, Y.; Zhang, X.; Korpelainen, H. Li C. 2010. Water deficit affects mesophyll limitation of leaves more strongly in sun than in shade in two contrasting Picea asperata populations. Tree Physiology 29: 1551-1561

Dwelle, R.B.; Kleinkopf, G.E.; Steinhorst, R.K.; Pavek, J.J.; Hurley, P.J. 1981. The influence of physiological processes on tuber yield of potato clones (Solanum tuberosum L.): stomatal diffusive resistance, stomatal conductance, gross photosynthesis rate, leaf canopy, tissue nutrient levels and tuber enzyme activities, Potato Res. 24 (1981): 33-47.

Flexas, J.; Medrano, H. 2002. Droughtinhibition of photosynthesis in C3 plants: stomatal and non-stomatal limitations revisited. Annals of Botany 89: 183-189.

Galmés, J.; Conesa, M. A.; Ochogavía, J. A.; Perdomo, J. A.; Francis, D.; Ribas, M.; Savé, R.; Flexas, J.; Medrano, H. Cifre J. 2011. Physiological and morphological adaptations in relation to water use efficiency in Mediterranean accessions of Solanum lycopersicum. Plant, Cell and Environment 34: 245-260.

Gaspar, T. T.; Franck, B.; Bisbis, C.; Kevers, L.; Jouve, J.F.; Hausman, J. 2002. Concepts in plant stress physiology. 
Application to plant tissue cultures. Plant Growth Regul. 37: 263-285

Hall, A.E. 1999. Cowpea in: Smith D.L., Hamel C. Crop yield, physiology and processes, Springer-Verlag Berlin Heidelberg, 1999, p. 355-373.

Hsiao, T. C. 1973. Plant responses to water stress. Ann. Rev. Plant Physiol. 24: 519570.

Huaman, Z.; Ross, R.W. 1985. Updated listing of potato species names, abbreviations and taxonomic status. American Potato Journal 62: 629-641.

Jaleel, C. A.; Manivannan, P.; Wahid, A.; Farooq M., Aljuburi H. J., Somasundaram R., Panneerselvam R. 2009. Drought Stress in Plants: A Review on Morphological Characteristics and Pigments Composition. International Journal of Agriculture $\mathrm{y}$ Biology 11 (1): 100-105.

Jaleel, C.A.; Manivannan, P.; Sankar, B.; Kishorekumar A., Gopi R., Somasundaram R. Panneerselvam R. 2007. Induction of drought stress tolerance by ketoconazole in Catharanthus roseus is mediated by enhanced antioxidant potentials and secondary metabolite accumulation. Colloids Surf. B: Biointerfaces 60: 201206

Jaleel, C.A.; Manivannan, P.; Lakshmanan, G.M.A.; Gomathinayagam, M.; Panneerselvam, R. 2008. Alterations in morphological parameters and photosynthetic pigment responses of Catharanthus roseus under soil water deficits. Colloids Surf. B: Biointerfaces 61: 298-303

Jerez, E.; Torres, W.; Dell'Amlco, J.; Morales, D. 1991. indicadores fisiológicos y bioquímicos en el cultivo de la papa en respuesta al estrés hídrico. Instituto Nacional de Ciencias Agrícolas. Cultivos Tropicales 12 (3): 30-38.

Jerez, E.; Torres, W.; Reynaldo, I. 1993. Indicadores fisiológicos y bioquímicos en cultivares de papa sometidos a estrés de humedad por periodos cortos de tiempo. Cultivos tropicales. 14 (2-3): 46-55.

Ku, S.B.; Edwards, G.E.; Tanner, C.B. 1977. Effects of light, carbon dioxide and temperature on photosynthesis, oxygen inhibition of photosynthesis and transpiration in Solanum tuberosum, Plant Physiol. 59: 868-872.

Kumar, R.; Kang, G.S. 2006. Usefulness of Andigena (Solanum tuberosum ssp andigena) genotypes as parents in breeding early bulking potato cultivars. Euphytica 150: 107-115.

Levitt, J. 1980. Responses of plants to environmental stresses. Academic Press, New York.

Mamani, P.; Ledent, J. F. 2014. Efecto de la sequía en la morfología, crecimiento y productividad de genotipos de papa (Solanum tuberosum L.) en Bolivia. Revista Latinoamericana de la papa 18 (1): 25-76.

Martinez, C.A.; Moreno, U. 1992. Expresiones fisiológicas a la sequía en dos variedades e papa sometidas a estrés hídrico en condiciones de campo. Revista Brasilera de Fisiología Vegetal 4 (1): 3338.

Medrano, H.; Flexas, J.; Galmés, J. 2009. Variability in water use efficiency at the leaf level among Mediterranean plants with different growth forms. Plant and Soil 317: 17-29.

Miyashita, K.; Tanakamaru, S.; Maitani, T.; Kimura, K. 2005. Recovery responses of photosynthesis, transpiration, and stomatal conductance in kidney bean following drought stress. Environ Exp Bot 53: $205-214$

Moorby, J.; Munns, R.; Walcott, J. 1975. Effect of water deficit on photosynthesis and tuber metabolism in potatoes, Aust. J. Plant Physiol. 2: 323-333.

Passioura, J.B. 1996. Drought and drought tolerance, Plant Growth Regul. 20: 79-83. 
Prasad, J. 1996. Plant Ecophysiology. John Wiley \& Sons, Inc., India.

Radin, J.W. 1981. Water relations of cotton plants under nitrogen deficiency. III. Stomatal conductance, photosynthesis, and abscisic acid accumulation during drought. Plant Physiology 67: 115-119.

Rambal, S.; Debussche, G. 1995. Water balance of Mediterranean ecosystems under a changing climate. Páginas: 386407 En: J. M. Moreno y W. C. Oechel, edit. Global change and Mediterraneantype ecosystems. Springer Verlag, New York.

Razmjoo, K.; Heydarizadeh, P.; Sabzalian, M.R. 2008. Effect of salinity and drought stresses on growth parameters and essential oil content of Matricaria chamomile. Int. J. Agric. Biol. 10: 451-454

Reichstein, M.; Tenhunen, J.D.; Roupsard O.; Ourcival, J.M.; Rambal, S.; Miglietta, F.; Peressotti, A.; Pecchiari, M.; Tirone, G.; Valentini, R. 2002. Severe drought effects on ecosystem $\mathrm{CO} 2$ and $\mathrm{H} 2 \mathrm{O}$ fluxes at three Mediterranean evergreen sites: revision of current hypotheses? Global Change Biology 8: 999-1017.

Richards, R.A. 1996. Defining criteria to improve yield under drought, Plant Growth Regul. 20: 157-166.

Robertson, J.M.; Pharis, R.P.; Huang, Y.Y.; Reid, D.M.; Yeung E.C. 1985. Drought-induced increases in abscisic acid levels in the root apex of sunflower. Plant Physiology 79: 1086-1089.

Rouhi, V.; Samson, R.; Lemeur, R.; Van Damme P. 2007. Photosynthetic gas exchange characteristics in three different almond species during drought stress and subsequent recovery. Environ Exp Bot 59: 117-129

Tai, G.C.C.; Tarn, T.R. 1980. Multivariate analyses of potato hybrids. 2 . Discrimination between TuberosumAndigena hybrid families and their relationship to their parents. Canadian
Journal of Genetics and Cytology 22: 279286.

Taiz L. Zeiger E. 2006. Plant hysiology. 4th ed. Sinauer Associates, Sunderland, MA. Leung, J. y J. Giraudat. 1998. Abscisic acid signal transduction. Ann. Rev. plant Physiol. Plant Mol. Biol. 49: 199-222.

Terradas J. 2001. Ecología de la vegetación. De la ecofisiología de las plantas a la dinámica de comunidades y paisajes. Ed. Omega, Barcelona.

Tourneux C., Devaux A., Camacho M.R., Mamani P., Ledent J.L. 2003. Effect of water shortage on six potato genotypes in the highlands of Bolivia (II): water relations, physiological parameters. Agronomie 23: 181-190 181 INRA, EDP Sciences.

Tuberosa R., Giuliani S., Parry M.A.J. Araus J.L. 2007. Improving water use efficiency in Mediterranean agriculture: what limits the adoption of new technologies. Annals of Applied Biology 150: $157-162$.

Turner N.C. 1979. Drought resistance and adaptation to water deficits in crop plants, in: Staples (Ed.), Stress Physiology in Crop Plants, J. Mussel and R.C. Wiley Interscience, New-York, 1979, p. 344-372.

Smirnoff N., 1993. The role of active oxygen in the response of plants to water deficit and desiccation. New Phytol. 125: 27-58

Soolanayakanahally R.Y., Guy R.D., Silim S.N., Drewes E.C., Schroeder W.R. 2009. Enhanced assimilation rate and water use efficiency with latitude through increased photosynthetic capacity and internal conductance in balsam poplar (Populus balsamifera L.). Plant, Cell \& Environment 32: 1821-1832.

Souza R.P., Machado E.C., Silva J.A.B., Lagoa A.M.M.A., Silveira J.A.G. 2004. Photosynthetic gas exchanges in cowpea 
(Vigna unguiculata) during water stress and recovery. Environ Exp Bot 51: 45-56

Spitters, C.J.T.; Schapendonk, A.H.C.M. 1990. Evaluation of breeding strategies for drought tolerance in potato by means of crop simulation, Plant and Soil 123: 193203.

Vacher, J.J.; García, M. 1990. Uso consuntivo y comportamiento hídrico de la papa amarga (Solanum juzepzukii) y de la papa dulce (Solanum tuberosum ssp andigena) en el altiplano boliviano. ORSTOM-SENAMHI. Bolivia. P 69-76

Valladares, F. 2004. Ecología del bosque mediterráneo en un mundo cambiante. Ministerio de Medio Ambiente, p 163190., EGRAF, S. A., Madrid. ISBN: 848014-552-8.

Vasquez, C.; Shrinivasrao, P.; Alexander, V.; Jonathan, I.; Watkinson, V.K.S.; De Koeyer, D.; Schafleitner, S.; David, B.W.;
Bonierbale, M.; Bohnert, H. J.; Grene, R. 2008. Physiological and molecular adaptations to drought in Andean potato genotypes. Journal of Experimental Botany 59 (8): 2109-2123.

Vos, J.; Groenwold, J. 1988. Water relations of potato leaves. I. diurnal changes gradients in the canopy and effects of leaf-insertion number cultivar and drought, Ann. Bot. 62: 363-372.

Weisz, R.; Kaminski, J. Smilowitz, Z. 1994. Water-deficit effects on potato leaf growth and transpiration: utilizing fraction extractable soil-water for comparison with other crops. American Potato Journal 71: 829-840.

Zyalalov, A.A. 2004. Water flows in higher plants: physiology, evolution, and system analysis. Russ. J. Plant Physiol. 51(4): 547-555. 